

\section{EXCHANGE}
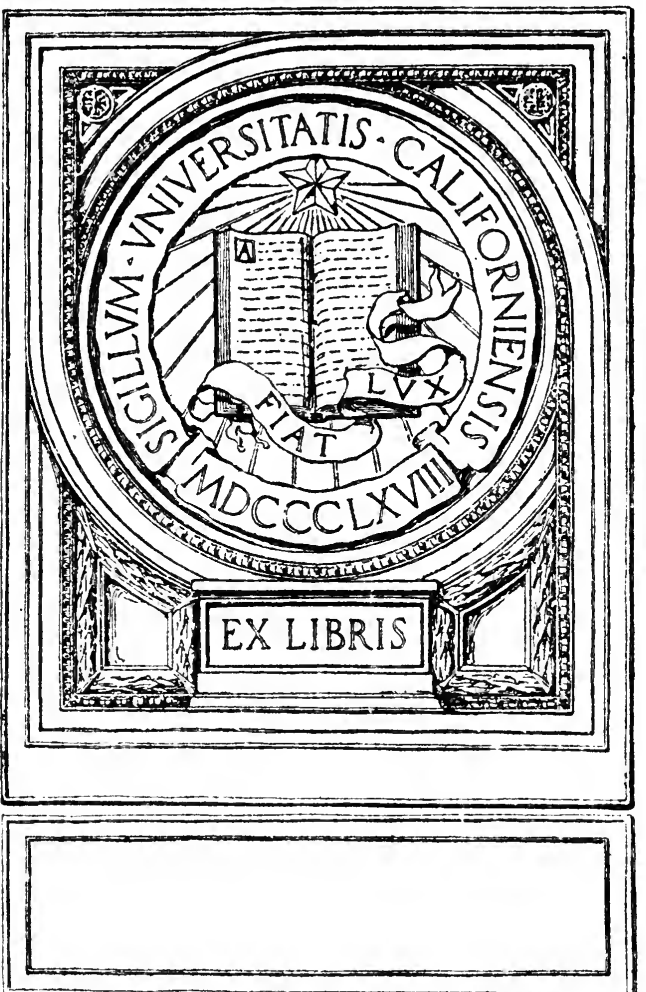


\section{A Contribution to the Pedagogy of Arithmetic}

BY

ERNEST C. McDOUGLE

Clark University

A DISSERTATION SUBMITTED TO THE FACULTY OF CLARK UNIVERSITY, WORCESTER, MASS., IN PARTIAL FULFILLMENT OF THE REQUIREMENTS FOR THE DEGREE OF DOCTOR OF PHILOSOPHY, AND ACCEPTED ON THE RECOMMENDATION OF WILLIAM H. BURNHAM.

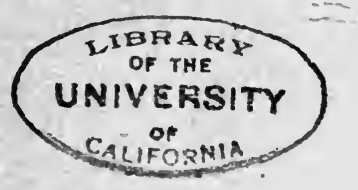

Reprinted from the Pedagogical Seminary

June, 1914, Vol. XXI, pp. 161-218 


\title{
A Contribution to the Pedagogy of Arithmetic
}

\author{
BY \\ ERNEST C. McDOUGLE
}

Clark University

\begin{abstract}
A DISSERTATION SUBMITTED TO THE FACULTY OF CLARK UNIVERSITY, WORCESTER, MASS., IN PARTIAL FULFILLMENT OF THE REQUIREMENTS FOR THE DEGREE OF DOCTOR OF PHILOSOPHY, AND ACCEPTED ON THE RECOMMENDATION OF WILLIAM H. BURNHAM.
\end{abstract}


$M z$

$\because$

औ 


\title{
A CONTRIBUTION TO THE PEDAGOGY OF
}

\section{ARITHMETIC*}

\author{
By ERnest C. McDougle, \\ Clark University
}

\section{Introduction}

Nearly three centuries ago Comenius undertook to give a method to teaching. At the present time there is a widespread movement through Experimental Education to establish it upon a sound scientific basis. Much that now finds acceptance in both curriculum and didactic procedure has found a place through conservative respect to traditional philosophies and dogmas of the past, coupled with some later

* It is fitting that I should here acknowledge my indebtedness to Dr. G. Stanley Hall, President of Clark University, for suggesting the field of investigation which led to this thesis, and for helpful direction in its development; to Dr. William H. Burnham, Professor of Pedagogy and School Hygiene, for his many favors in suggesting material to be embraced in the research upon the thesis and for valuable criticism of the treatment of the topics included; to Dr. Louis N. Wilson, Librarian of Clark University, for his unsparing pains in procuring special documents for my use in gathering data; to Dr. S. A. Courtis, of Detroit, Mich., for the loan of some private materials; and to Miss Rose A. Carrigan, of the Boston Normal School, whose kindness made it possible for me to witness the recent tests of the Boston school children and to be furnished with additional statistical facts.

I wish also to thank the following persons for prompt response to my personal letters asking about material to be included in my survey: Dr. E. L. Thorndike, of Columbia University; Dr. G. Deutchler, Tübingen, Germany; Dr. A. W. Stamper, Chico, Cal.; Dr. W. H. Maxwell, Superintendent New York City schools; Mrs. Adelia R. Hornbrook, San Jose, Cal.; Prof. J. E. Calfee, Berea, Ky.; and Prof. C. H. Dietrich, Winchester, Ky. 
empirical and pragmatic considerations. The present critical studies and experiments are concerned with both the subjects in the curricula and the methods of instruction. In these researches many laboratories have been busy, many investigators have been active, and much helpful work has been done. It is now necessary that the results should be brought together and put into usable form. Experimental Psychology has been too busy in exploring many fertile fields, as yet, to give attention to the full bearing of its discoveries upon Didactics, while Experimental Pedagogy is frequently too empirical to be scientific. For these reasons it is essential that the synthesist should bring together the modern needs of Pedagogy and the contributions of Experimental Psychology germane to the processes of learning, and state in clear and simple language the norms of method so the average teacher, who possesses little or no technical nomenclature of the psychological laboratory, or even of the experimental pedagogist, may find assistance in the daily routine of school duties.

It is the purpose of this research to bring together many of the recent tests and experiments in Arithmetic and, in connection with conclusions drawn from them bearing upon better texts and methods, to evaluate them for practical use in the regular school work.

\section{Brief Historic Sketch of Arith metic}

Arithmetic is the oldest science developed by man. As an art it runs much farther back into antiquity. Its first use is so remote that it is difficult to separate the mythical from the real. Anthropological investigations have brought much helpful material to light and the historical genesis of Arithmetic is coming to be better understood.

Callisthenes found in Babylon, in 33 $\mathrm{I}$ B. C., when Alexander the Great captured the city, burned brick astronomical records running back to $2234 \mathrm{~B}$. C. These were sent to Aristotle, according to Porphyry. In Egypt no uncivilized state of society has been found. Their oldest mathematical books date back to 3400 B. C., although Josephus (62, chap. 7 , p. 50) gives Abraham credit for introducing Arithmetic into Egypt, when he says:

" $\mathrm{He}$ communicated to them Arithmetic and delivered to them the science of Astronomy, for before Abram came into Egypt they were unacquainted with those parts of learning, and that science came from the Chaldeans into Egypt, and from thence to the Greeks also."

Among the Greeks and Romans, as well as among most 
primitive peoples, systems of counting were clumsy and imperfect, and it became necessary to invent symbols for numbers and systems of numeration for the practical use of these symbols. Counting-boards and the abacus were early invented and have persisted down to the present time. We find the Chinese and Japanese (64, 179) using the swan-pan and the soroban very generally even to-day. It is of historic interest to note that the first printed Arithmetic, published at Treviso, near Venice, was entitled "The Art of the Abacus for Arithmetic." Because of their awkward number symbols the Romans used calculating-boards for computations and employed their symbols only in stating results. The process of calculation derives its name from the Latin, calculus, " pebble," since pebbles were used as counters by many people around the Mediterranean.

The so-called Arabic characters are more properly Hindu. Leonardo of Pisa, in I200 A. D., obtained them from the Moors and two years later he published a system of computation using them. As he had obtained the characters from the Arabs they received the name Arabic. They have been traced, however, to the Hindus. After their introduction into Europe, a long contest ensued between the abacists and the algorists, but the Hindu system gradually spread over the continent and was well known by 1400 A. D. Merchants discarded the Roman notation in $155^{\circ}$ and the monasteries and colleges followed a century later. With the new system, Florentine traders and writers developed double-entry bookkeeping and worked out seven operations: Numeration, Addition, Subtraction, Multiplication, Division, Involution, and Evolution, while Italian and English arithmeticians simplified the processes. The Arabs added from left to right. Garth, an Englishman, devised a plan to add from right to left. One has only to compare the solution of a problem in Division by Pacioli or Tartaglia with the work done even in the third grade of the schools to-day to note what simplification has taken place.

The invention of printing with movable types, together with the great commercial activity carried on through the Hanseatic League and other agencies gave a remarkable stimulus to algoristic Arithmetic in Europe. In the sixteenth century sweeping transitions occurred. The manuscript Arithmetics were replaced by printed books; Roman symbols yielded to the Hindu characters; the Arithmetic of the learned became the possession of the common people; and counters disappeared in favor of figures. Many authors were found in Italy, France, Germany, Holland, and England, and the art of reckoning with the pen rapidly replaced the art of calcu- 
lating with the abacus. The Hanseatic League established Rechenschulen along its trade routes and these commercial schools had much to do in keeping Arithmetic out of the regular schools. The first German Arithmetic appeared in I482 from the pen of Ulrich Wagner, a Rechenmeister of this League. Many topics, such as Partnership with Time, came into use then as a practical business subject, and have been retained in our modern text-books long after the business world has discarded the methods they present. It was through the influence of Pestalozzi that Arithmetic was given such a prominent place in the schools. Despite strenuous efforts to discredit its value and to minimize its standing among the branches of learning in recent years, it is still receiving from $12 \%$ to $26 \%$ of the entire time devoted to recitation in the Elementary Schools throughout the civilized countries of the world ( 90$)$.

\section{Psychology of Arithmetic}

The big question among teachers is to know how to teach according to sound principles. As with other subjects in the curriculum, scientific methods in Arithmetic must ultimately be based upon genetic psychology. Until we approach from the lower side the many questions of material and method, there will be only an approximation to the real solution. Most methods have been superimposed, so to speak, upon the child from above and only in late years has there come any decided scientific tendency to study the genesis of number and the processes of computation from the child's point of view. These studies are yet confessedly few and do not warrant an attempt at a full statement of scientific method based upon them. What has been learned may assist in better pedagogical procedure and incite to further original research.

Genesis of Number Ideas.-Major (75, 167) observed his son among other things for the rise of his ideas of number. $\mathrm{He}$ found him able to miss one ball out of his wagon, when three were in it, at the age of 21 months. While the child had a confused idea of 3,4 , and 5 , at three years of age, Major received, many times, the correct number, 1 , or 2 , or 3 , when apples were used, by throwing them on the ground and asking for a certain number. Later, the child's interest declined. Preyer's boy missed one of his ro toys $(75,166)$, at the age of only 18 months, and at 878 days of age counted his nine-pins by standing them in a row and saying: "Eins! Eins! Eins! Noch Eins! Noch Eins!" and so on to the end of the row. On her 584th day, Dearborn's little daughter 
(32a, I76) counted 6 cattle in a picture by saying: "One, two; one, two; one, two." He thinks she knew the number 2 as early as the 543 rd day, and also says the same thing about I. Decroly thinks his little girl knew 2 before she recognized what $I$ is (33a, II9). The 2 seemed to remain for some time as the only number the child grasped. Binet's daughter at 30 months of age comprehended 2, and could get the idea of 4 at $5 \mathrm{I}$ months (33a). Lindner's son at 23 months had the number 2 (33a). Moore's three children had the idea of 2 at 22, 26, and 29 months; and a good idea of 3 at 32 , and 53 months. Scupin's child (33a) knew 2 at 22 months.

Clara and William Stern studied their children very carefully and report that they could use numbers correctly in connection with apples, for instance, long before the abstract idea of number arose, or even before number could be rightly applied to other objects of less interest (33a). Ordinals were learned before cardinals. Major reports ordinals and cardinals as confusing to his child (75, 173), while Hilde Stern could get the fifth finger, but did not seem to understand the sum of her fingers and thumb on one hand (74a). Decroly made many careful observations upon his daughter and contributes a very interesting opinion that she knew the number 2 long before she had the idea of $\mathrm{r}$. This does not seem to have been observed by others who have studied the genesis of number in infants and deserves to have more attention. While his child got the idea of two at 19 months of age, she was able to differentiate three, at 28 months, from two or one. In another month she picked out 2 objects by the aid of her fingers, and at 35 months did this without using the fingers. At $4 \mathrm{I}$ months, she seemed to have the idea of 3 quite well in mind and in another month the idea of 4 appeared to be somewhat clear. Still, as many other childobservers have found in their studies, there was a reversion of both interest and apparent ability later, and at 46 months of age the little girl had a confused idea of 3 and 4 , calling them simply, " more." At $5 \mathrm{I}$ months, 3 arose again to clearness and soon was well comprehended. By her 57 th month she was able to hand the correct number of objects, up to 5 , indicated by having held up for her problem one or more fingers. This showed an ability to abstract the idea of number, say from four fingers held up by her father, and of applying the number thus gained to the apples or other objects asked for. Sully found his child at 4 years 3 months calling big beads " 6 ," smaller ones, " 5 ," and still smaller ones, " 4." At 5 years old, however, he placed four crabapples upon the sand, added two to them mentally, and begin- 
ning with calling the first one " 3 ," counted them correctly up to 6 . He could also count his four playthings, two dolls, a tin soldier, and a shell, from memory, after they had been put away. Sully says (I2I, 352) that the drawings of children 5 years of age show small regard for the five fingers of the hand. In the growth of infants in number ideas we find marked individual differences, and it can only be said yet that the idea of number seems to be forming intelligently about the fourth year $(75,165)$.

Lietzmann $(72,22)$ thinks schools often make a mistake in proceeding as if the child has no ideas of number when it enters school. "The beginnings of number lie much earlier. When the child comes to school, it will, in a majority of cases, already know the number words possibly up to I0, or 12." Of 1,217 children entering the Volksschulen in Breslau, 10\% could count up to $5,78 \%$ could count up to IO, $4 \%$ up to 100 , and nearly $1 \%$ over 100 .

Bailard says $(9,58)$ : "It is a well known fact that children learn to count of their own accord. They do it at home, on the playground, and at their games. It is impossible to stop them." "I tested a school where no counting is especially taught and found that about $60 \%$ of the children could count up to 20 , before they were 5 years old, and about $30 \%$ could count up to 30 before they were 6." Meumann (79, Bd. 2, 345) agrees with Preyer and the other few child psychologists that the child has a somewhat fully intelligible use of numbers from $I$ to $I 0$ at the earliest toward the close of the 4th year of its life. In his report of the Fielden School, Manchester, Eng., Harrison $(54,269)$ says the children play with dominoes and "the result is, that already the five-year olds are able to write correctly on the blackboard the result of 2 plus 7,9 plus 5, etc." This agrees with Montessori who has children at three to begin counting with buttons, plates, or money, and later with sets of blocks.

There are two very distinct schools of educators on the question of the origin of the child's notion of number. One party maintains that ideas of number are developed through the simultaneous perception of several objects, or stimuli, presented to the senses. With Newcomb (87) they hold that "our teaching of numbers is too abstract,- too much dissociated from objects of sense." Many experiments have been performed in recent years to determine how many objects one may be able to apprehend accurately without counting. For this purpose the time exposure is made as brief as possible so as to prevent counting. Nanu (86) used bright dots on a dark background and gave a time exposure of $33 / 1000$ of a second. She ar- 
ranged the dots in different figures and found that 5 could be perceived in a line, 10 in a parallelogram, and 8 in a hexagon in $75 \%$ of the cases. Lay (67) performed many experiments and found a greater percentage of successes attended the arrangement of dots in quadrate form. He is a strong advocate of the objective method of teaching the early number work. He quotes the experiments of Goldscheider and Müller, von Scheele, Schneider, Külpe, Cattell, Dietze, Warren and Messenger in support of his claims. However, his contentions are not without vigorous criticism from Walsemann, Knilling, Knoche, and the whole school of Herbartians. McLellan and Dewey (76) would base the development of number upon measuring,-upon the ratio idea. They hold that there is no number without measurement (p. 242) nor measurement without the fraction implied. Tear reviewed the Speer arithmetic a half generation ago and quotes Newton (123, 63I ): "Number is the abstract ratio of one quantity to another quantity of the same kind." So, also, the great Swiss mathematician, Euler, is cited: "Number is the ratio of one quantity to another quantity taken as a unit."

In direct opposition to this notion of the origin of number in the child mind and to the consequent procedure in teaching, there is a strong party which maintains that the presentation of the objects in a series, or the stimuli in succession, is the proper method. Gilbert (43, I IO) believes that counting is "the first step in systematic thinking," while Phillips decides $(95,227)$ that "the first step is surely the formation of the series-idea." $\mathrm{He}$ holds that counting is fundamental, and that children forbidden to count on their fingers sometimes count by using their toes, or move an elbow, or press a muscle, or clear the throat slightly in order to follow the series. Among his reasons for rejecting the Grube method, Badanes says $(6,34)$ : "It is false from the point of view of Arithmetic as a science and as an art. It ignores the process of counting." The dispute really carries us back into the philosophical question as to whether number has time-relation only, or space-relation only, or neither, or both. It will suffice to present the writer's view on the pedagogical significance of the discussion to quote with approval the words of Meumann $(79,338)$ : From the psychological point_of view number-concepts seem to possess both temporal and spatial qualities, and either of the views alone represents necessarily a one-sided notion, that by the series-method and by the simultaneous-method the child gains something of power not contained in the other. "The fact that by both methods good results can be obtained shows that a complement of these methods, or the simultaneous employment of 
both, must be the right way of complete comprehension of number for the child."

On the side of anthropology, many systems of notation have been found among primitive peoples, and no definite correlation seems to exist between these systems and the civil development of the tribes. The highly civilized Peruvians knew almost no arithmetic as an art and nothing of it as a science, according to Conant (24, I50), while the Yorubas, a very barbarous tribe in Africa could count quite expertly. Many savage tribes count only up to two, and have number words only for "one," "two," and "many" or some other verbal device for distinguishing their first definite number ideas from the indefinite ones lying beyond. The lowest Brazilian tribes count to 3, and the Carribees, Galibi, Abipones and many others go up to 4 . As a rule the South American and Australian tribes count seldom above 3 or 4 . Among some of the Australians only binary systems prevail, while ternary and quaternary systems abound among the Indian tribes of South America. Yet, some Pacific island tribes have been found with ability to count up into millions in their trade in fish and breadfruit. Quinary scales are widely diffused throughout the world, and a few octonary systems are believed to have existed. Some scant traces of vigesimal systems have been found. All these facts show how slowly and imperfectly the concept of number has arisen among primitive peoples, who seem to have used numbers only as necessity forced the matter upon them. Need for counting in their barter with one another had more influence upon number than did their general intelligence, or any subjective interest in it. Conant $(25,3 \mathrm{I})$ says:

"If the life of any tribe is such as to induce trade and barter with their neighbors, a considerable quickness in reckoning will be developed among them. Otherwise this power will remain dormant because there is but little in the life of primitive man to call for its exercise."

More recently Boas (10, 65-66) has stated this as follows:

"The fact that generalized forms of expression are not used does not prove inability to form them, but merely proves that the mode of life of the people is such that they are not required; that they would, however, develop just as soon as needed. This point of view is also corroborated by a study of the numeral systems of primitive languages. As is well known, many languages exist in which the numerals do not exceed two or three. It has been inferred from this that the people speaking these languages are not capable of forming the concept of higher numbers. I think this interpretation of the existing conditions is highly erroneous. Peoples like the South American Indians (among whom these defective numeral systems are found), or like the Eskimo (whose old system of numbers probably did not exceed ten), are presumably not in need of 
higher numerical expressions, because there are not many objects that they have to count. On the other hand, just as soon as these same people find themselves in contact with civilization, and when they acquire standards of value that have to be counted, they adopt with perfect ease higher numerals from other languages and develop a more or less perfect system of counting. . . . It must be borne in mind that counting does not become necessary until objects are considered in such generalized form that their individualities are entirely lost sight of. For this reason it is possible that even a person who has a flock of domesticated animals may know them by name and by their characteristics without ever desiring to count them. Members of a war expedition may be known by name and may not be counted. In short, there is no proof that the use of numerals is in any way connected with the inability to form concepts of higher numbers."

It may not be an unfair or unwarranted deduction from all these studies and views to believe that children at school entrance in America may have ample ability to delight in numbers although they may show little interest in them up to that time. The child-mind no doubt expands intelligently with its growth in experience with objects of multitude, much as the development of the primitive mind does, as described by Boas. Its early work with these numbers can be motivated and made attractive in a manner paralleling the race expansion. "The child is a natural symbolist," says Mary R. Alling-Aber ( 3 , I7I). "A corn-cob with a dress on it will do for a baby and a stick with no additions, for a horse. To let one thing stand for another is as easy to a child as to breathe." There is an easy transition from the objects, too, to numbers and then from numbers to symbols at an age corresponding to school entrance.

Time of Beginning Arithmetic.-With regard to the time when Arithmetic should be introduced into the schools and when it should be completed there is some difference of opinion, and the matter is just now in the polemical stage. One group of educators holds that it should not be taught, except incidentally, in the first grade, or first and second, or the first three grades. The majority report of the Committee of Fifteen of the National Educational Association, in 1895, urged the beginning of the subject in the second and its completion in the sixth grade. Burnham ( 17,65$)$ believes there is "ample reason for postponing the work of Arithmetic until the age of Io, or, more accurately, to that stage of development which is likely to be found in normal children at this age. While it is greatly to be desired that more investigations be made in regard to this subject, with our present experience this seems to be a wise rule." Chartres $(22,278)$ says that "separate Arithmetic classes should not be taught in the first grade; it is better to defer them to the second 
grade, and probably it would be better to begin Arithmetic in the fourth grade if our text-books were built with that in view." So also writes Stamper (II3, 258): "The general tendency in this country is to refrain from all drill work in the first year. In fact, some schools defer such work until the middle of the second year, or the beginning of the third."

On the other side of the controversy are to be found many ardent protagonists. Smith (I05, I28) says: "Not to put Arithmetic as a topic in the first grade is to make sure that it will not be seriously or systematically taught there in ninetenths of the schools of the country. The average teacher, not in the cities merely, but throughout the country generally, will simply touch upon it in the most perfunctory way. Whatever of scientific statistics we have show that this is true, and that children so taught are not, when they enter the intermediate grades, as well prepared in Arithmetic as those who have studied the subject as a topic from the first grade on." In a very recent article (I06, 95) he further argues: "All the talk about having no Arithmetic in grades I and 2, or leaving it to the whim of the teacher, has not shaken the belief of the great schools of the world in the wisdom of Pestalozzi's judgment." "Arithmetic is a game and all boys and girls are mere players. We have not learned this very thoroughly yet, but we are making progress." Montessori $(83,326)$ claims to achieve some wonderful results even with children of pre-school age. Greenwood (47) dissented from the report of the Committee of Fifteen and furnished a verbatim report of some actual teaching and results in the Kansas City Schools as proof of his contention that Arithmetic is eminently successful in the lower grades. "No greater difficulty to get small children to grasp the nature of a fraction as such than in getting them to grasp the simple whole numbers. . . . Children get the idea of half, third, quarter, long before they enter school." Hence, he advocates teaching them to add, subtract, multiply and divide fractions in the first grade. Cook ( 7 ) says: "I visited the Kansas City schools and testify that Mr. Greenwood has not overestimated conditions. I took some third-grade work home and tried it on Normal students, and they couldn't do it as rapidly as those children did it." In Germany a little more than $20 \%$ of the time in the first two grades is devoted to Arithmetic. In the United States, according to the report formulated in I9I I by the American Committee of the International Commission on the Teaching of Mathematics ( 56 , I6-65, 75-78) cities reporting about one-tenth of the school population of the country show that Arithmetic is taught as a topic in the first grade in $71.5 \%$; in the second grade it 
is introduced in $22 \%$; and in the third grade in $6.5 \%$. (See Table $\mathrm{E}$ for further details.) In country, or rural schools, it may be said to be taught in the first grade in practically all the schools.

The writer personally believes that there should be systematic teaching of numbers in the first grades. The child's natural interest in numbers and the rich opportunities for presenting numbers in concrete objects should be utilized. Mere rote work must be avoided, but these early years are of inestimable value in furnishing a substantial foundation in the child's individual growth in the comprehension of numbers. Counting may also be used in these grades to diversify the work and add to the useful results.

Utility and Discipline.-Another question of much interest and one upon which there is considerable controversy yet, is that of the so-called disciplinary value of Arithmetic. The matter is at least as old as Plato, who says in his Republic: "And you have further remarked that those who have a natural talent for calculation are generally quick at every other kind of knowledge, and even the dull, if they have arithmetical training, gain in quickness, if not in any other way." In mathematics, perhaps, more than in any other subject, the doctrine of formal discipline, or transfer of training, has been most successfully maintained. If Arithmetic has not been kept in the curriculum as a practical subject it has staid there as a disciplinarian of the intellect. John Stuart Mill attributed his success in speculation to his mathematical training,- " the habit of never accepting half solutions of difficulties as complete, never abandoning a puzzle, but again and again returning to it until it was cleared up; never allowing obscurities in a subject to remain unexplained because they did not seem important; never thinking I perfectly understood any part of a subject until I understood the whole." This is not the place to discuss the general question of mental discipline, or transfer of training, upon which an extensive and varied literature has been produced within the past decade. It is not well to accept either of the two extreme positions noted in the literature, but at present the value of arithmetic in the school course may be defended upon both practical and disciplinary grounds. In its utilitarian aspects the demands of every-day commercial life are sufficient proof. And on the subjective side, if it should be shown that one intellectual trait does not and cannot assist any other, still the Einstellung toward matters under consideration trained into children in Arithmetic may be advanced as evidence of the subjective discipline of Arithmetic. 
The certainties found in Arithmetic, too, have a moral value to children as they approach so much of uncertainty in other studies.

\section{Experimental Studies}

Many experimental studies of the teaching of Arithmetic and the various processes of learning the different operations in handling numbers have been made, notably within the past two years. While they have been concerned principally with only the fundamental operations, a synthetic study of their results should throw some added light upon our problem of finding a scientific basis for Arithmetical Methods. Thousands of children have been tested and drilled under more or less controlled conditions, and the results are now becoming available for comparative pedagogical purposes. Much yet remains to be learned by further experimentation, but a consideration of those studies that have been made and published will assist materially in determining more clearly than has been done heretofore the weakness of the present methods, their strong features, and suggest the next step in the search for a sound pedagogy of Arithmetic.

Influence of Puberty.-Voigt made some studies upon children from ten to fourteen years of age in the Volksschulen (80, II $)$. Instead of using the ordinary decimal system of notation, he employed systems in which 8 and 6 were the bases. By this means he reduced to a minimum the use of knowledge already possessed by the children. Among his results are these: I, The learning of new systems does not progress gradually, but by "leaps;" 2 , Between the ages of I 3 and I4 the boys showed a marked increase in ability; 3 , Between the ages of 12 and $I_{3}$ the girls showed this rise in ability. It was noticed that the onset of puberty gave a decided increase in the ability to work independently in numbers. Prior to this time the children as a rule work mechanically, according to "copy." The boys reached the period of independent work from $\mathrm{I}$ to $\mathrm{I} \mathrm{I} / 2$ years in physiological age later than the girls; hence, the girls of the same age as the boys after the beginning of puberty are usually more than one year ahead of them in number work. That is, problems which boys can solve independently in their eighth year in school can be as easily solved by girls in their seventh year. Rice and Courtis both found the 6th grade especially troublesome, as there were disturbances in the scores of that grade in the many records which they gathered. In the recent tests in Boston $(38,23)$ this errancy was found in the 7 th grade. Since Boston admits children at five years 
of age, the 7 th grade there would correspond to the 6 th grade in physiological age elsewhere. It appears from the tests of Voigt, Rice and Courtis that the dawn of adolescence, affecting as it does markedly the physiological nature of the child, has also a great effect upon its ability to do accurate and independent work with numbers. Before this time, mechanical work is done; after this period the rise of independence and self-reliance changes the emphasis to the reasoning phases of arithmetical solutions.

Value of Drill.-A number of experimental studies have been made to arrive at some fundamental facts concerning the value of drill. Brown (I3, 8Iff) gave the Stone tests to 6 th, 7 th, and 8th grades of the practice school of the Eastern Illinois State Normal School, consisting of 5 I pupils, I 8 boys and 33 girls. Two sections were made of them. One was drilled upon fundamentals for five minutes each day for thirty days, while the other pursued regular work. A test at the end showed that the drilled pupils made a much larger advancement than the others. His results also showed that the 6th grade children profited more from drill than did the next higher grades. Later, he carried his experiments into three school systems $(13,488)$, confining the tests to the 6 th grade and to the four fundamental operations. In all, he tested 222 pupils, I IO boys and II 2 girls. Only twenty days were allowed between the first and the second tests, during which time one group in each school was given five minutes extra drill in the fundamentals besides the regular work which the other section followed. The results showed a gain on the part of the non-drill group in problems solved of $6.4 \%$; in Addition, of $6.8 \%$; in Subtraction, of II.9\%; in Multiplication, of $10.9 \%$; in Division, of $15.4 \%$. The drill group gained on these same items respectively: $16.9 \%, 18.5 \%, 32 \%$, $24.1 \%$, and $34.2 \%$. These are only the aggregates. Of the I 2 cases of drilled pupils, 95 gained, 5 did not advance and I2 lost. Of the I IO cases of non-drilled pupils, 50 gained, 7 had the same score as at the beginning, and 53 lost. In the individual studies and aggregates submitted it appears that the drilled groups gained from two to three times as much as the non-drilled groups. "All teachers of the drill classes reported an improvement also in the text-book work." The drill excited them to keener interest in the regular lessons ( I3, 489).

In March, I912, Phillips (93) gave the Stone tests to 33 boys and 36 girls of the 6 th, 7 th, and 8 th grades. Each grade was divided into two groups, one pursuing regular work and 
the other receiving in addition a ten-minute drill daily upon fundamental operations and upon reasoning upon mental problems. At the end of two months the two groups were again submitted to the Stone test with the following results: 6 th grade non-drill, gain in Fundamentals, 55\%; drill group, $45 \%$; 7 th grade, in Fundamentals, non-drill, ro \%; drill group, $22 \%$; 8th grade, in Fundamentals, non-drill, $16 \%$; drill, $25 \%$; all grades, gain in Fundamentals, non-drill, $27 \%$; drill, $31 \%$. In Reasoning: the 6th grade gain was: non-drill, $36 \%$; drill, $55 \%$; 7 th grade, non-drill, I $7 \%$; drill, $29 \%$; 8th grade, nondrill, $12 \%$; drill, $15 \%$; all, non-drill, $22 \%$; drill, $33 \%$.

Starch (II4) gave I5 observers eight preliminary tests, six in arithmetical operations and two in auditory memory span for numbers. Of these observers, 8 were then given fourteen days' practice in mental multiplication of 50 problems each day, totaling 700 problems. The other 7 observers were given no practice. On the second test the practiced observers showed from twenty to forty per cent improvement more than the others in the arithmetical operations, while there was little change in the memory span in either group. Thorndike (125) experimented with 33 adults to learn the increase in efficiency in mental multiplication, judged by the reduction in the time required. He used no figure below 3 and none was repeated. All his subjects showed improvement through drill, and he says:

"The fact that these mature and competent minds improved in the course of so short a training so much as to be able to do an equal task in two-fifths of the time first taken is worthy of attention." "The most ardent advocate of the general influence of specific practice would not, I judge, claim that ten hours drill in any one thing could improve an already well-educated adult $50 \%$, or $5 \%$, or even $1 \%$ in the average of all kis intellectual processes."

He found a rapid rise in the rate of improvement during the early practice, an observation generally confirmed by all experimenters. At another time he used I9 adult subjects, 8 men and II women students in Columbia University, giving them each day for seven days 48 columns of ten figures each to add, in all 2,592 additions. These subjects were able on the second test to reduce the time $31 \%$ and the errors $29 \%$, with a total improvement of $29 \%$. Only fifty-three minutes' practice was actually given. Thorndike says of this test:

" That the practice represented by only 2,592 additions made by an educated adult whose addition associations have been long established and often used should produce an improvement of threetenths bears witness to the continued plasticity and educability of the synapses involved." 
In another connection he has stated (127, 290):

"So apparently simple an ability as ordinary addition of integers can be shown to require analysis into at least nine separate abilities, each of which probably requires further analysis, in one case, into perhaps ninety component ability-atoms."

Similarly, Donovan and Thorndike (128, 134) used 29 fourthgrade pupils and found in a practice series, given two periods of two minutes each per day for three school weeks, or a total of thirty two-minute periods, the average rose from $23 / 4$ to $4 \frac{1}{2}$ examples per minute. Kirby $(65,24)$ studied experimentally $73^{2}$ children in the fourth grade, testing them before and after sixty minutes of practice, after the method just mentioned. He found the average score changed from 3 I columns with 24 correct per minute to 50 columns with 37 correct. The children, therefore, gained $61 \%$ in attempts and $54 \%$ in correct additions, and maintained the same rate in their accuracy and in their speed, almost. Hahn (128, I34) has obtained similar results. Kirby also gave a series of drills for fifty minutes to 606 third and fourth grade children. At the beginning the children averaged 40 simple divisions per minute, with 37 correct, an accuracy of almost $93 \%$. At the close of the drill series they performed 73 divisions per minute with 70 correct, an accuracy of almost $97 \%$. They had gained $83 \%$ in speed and almost $90 \%$ in their accurate results. At McLean Hospital, Wells found that ten nurses, five men and five women, in oral addition of digits printed one above the other, in five weeks, practicing five minutes per day, six days in the week,-a total of I50 minutes of practice, increased their speed nearly 100\% and maintained about the same rate of gain in accurate work. The five women on the first day performed I,II 5 additions in five minutes, while the five men reached $\mathrm{I}, \mathrm{I} 2 \mathrm{O}$. On the thirtieth day the women aggregated 2,210, and the men 2,178 additions. The lowest score at first was made by a woman who got $\mathrm{I}_{50}$, and at the end she reached 280 . The highest at first was by a man who got 290 and on the thirtieth day he went to 540. It is observed that the lowest and the highest made practically the same rate of gain. Whitley (I34, I29) tested nine subjects in mental multiplication, giving a practice series of three examples per day for twenty days, omitting Sundays. These subjects averaged 2.8 minutes practice per day, or a total of fifty-six minutes. The results show more than $100 \%$ gain in speed, with no ill effect upon accuracy. In the Dumfries schools, Jeffrey $(61,392)$ selected 9 boys and 9 girls, and placed them in three groups according to their mental ability, as disclosed in previous school work. 
Each group consisted of three boys and three girls, the groups being classified as bright, average and dull. They were all given fifteen-minute drills for five consecutive days and then were tested with the following results: The 9 boys made 19,717 additions and the 9 girls made 18,304 , with 126 errors by the boys and I 34 errors by the girls. The group results were: bright boys gained from first to second day, 49.1\%, girls, $32.7 \%$; average boys, $28.2 \%$, girls, $32.3 \%$; dull boys, $25.7 \%$; girls, $44.6 \%$. From first to fifth day the gains were: bright boys, $90.9 \%$, girls, $58.9 \%$; average boys, $62.9 \%$, girls, $67.2 \%$; dull boys, $47.4 \%$, girls, $91.1 \%$.

Short and Long Periods of Drill.-Kirby tried the effect of dividing the total practice time into periods of different lengths. He used 1,338 children $(65,63)$ and his results have considerable pedagogic value. Using 100 as a standard of comparison his data may be expressed as follows: Gains made with 22-minute practice periods, 100 ; 15 -minute periods, I2I ; 6-minute periods, IOI ; 2-minute periods, I46.5. These were in addition. The results in division were: from 20minute periods taken as a basis, I00; IO-minute periods, I I0.5; 2-minute periods, 177 . That is, the short periods of practice scattered over more days give a higher rate of gain. These are subject, however, to discount since the children during the longer time elapsing from the first to the last test would gain more from their regular work than those taking the longer single periods of practice. In the Whitley tests already referred to it should be noted that after twenty days, with practice upon only three examples each day, the subjects were able to reduce the time from 338 seconds, with I.7 errors per example to I35 seconds with 1.4 errors per example. Thorndike drilled sixteen subjects continuously on sixty examples, the number used by Whitley, but employing only one period of practice, varying from 2 to 12 hours. His adult subjects took an average of 352 seconds per example with 1.2 errors on the first test, and 160 seconds with 0.8 errors on their final test. Their total time of practice averaged higher than did those tested by Whitley, while their gain was not so marked. However, it is to be noted that Thorndike's subjects took their final test at the close of three or four hours of unrelenting practice, and some allowance is to be made for their jaded condition.

Permanency of Improvement through Drill.-Wells tested for the permanence of improvement in the adult nurses who had taken the drill from January to April, I9Io, giving six of them two tests in December, I9I2, after a lapse of 2 years and 8 months $(128,323)$. In January, I9Io, they had 
averaged 234 additions in their first test and 274 on the second, while their average score in the final test in April, 1910, had been 447. In December, 1912, these same adults on their first test scored 343 additions and the next day raised it to 375 . Kirby $(65,7 \mathrm{Iff})$ tested 258 of his fourthgrade children from three to twelve weeks after they had relinquished their practice and found them able to do as well as they had done on their previous final tests. He again submitted 152 of them to tests in September, at the opening of school after the summer vacation, and they showed a decided loss in speed with some decrease in accuracy. Prac-

TABLE A

Twenty Leading "TYPE-ERrors," Made by Two Hundred and ThirtyEIGHT CHILDREN IN ADDITION OF DIGITS, ARRANGED IN ORDER OF FREQUENCY. COMPILED FROM PHELPS (92)

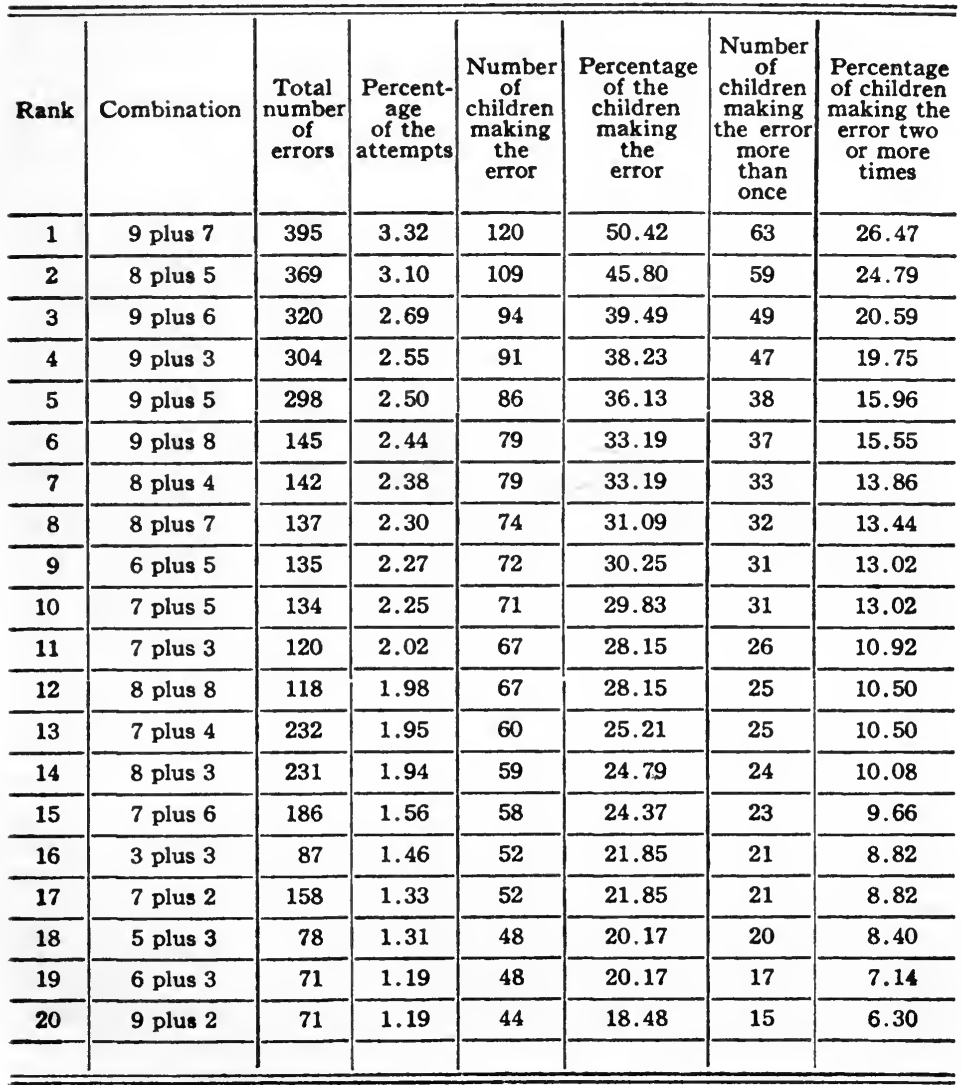


tice drills of fifteen to forty-five minutes were sufficient to restore the speed of the former tests. Brown (13) tested his practice school class, already discussed, after the summer vacation of twelve weeks and found that the drilled section in September was able to raise the averages made in June, while the undrilled section either showed no gain or had retrograded.

Type-Errors.-Phelps (92) reviews the Otis-Davidson tests upon 270 children in the eighth grade and uses their data in the study of errors. These tests were given in the grammar school at San Jose, Cal., and 238 sets of papers, 5,950 separate tests, were obtained. In Table A I have arranged the chief mistakes in addition in the order of their frequency.

There is a remarkably consistent showing in the table,the combinations, which were the more difficult as shown by the number of times they occur, are also those which are made by the largest number of children and are more often repeated by the same child than the other combinations. Of the eight schools reported, those showing the highest speed had the lowest percentage of accuracy.

Phillips $(95,245)$, out of 440 returns made to him, gives the following list of difficult combinations of the digits in addition: I 57 find 9 plus 7 the hardest; 88,7 plus $8 ; 34,6$ plus $7 ; 42$ find 7 alone troublesome; 18,9 only; 26 are bothered in using 3,6 , and $8 ; 327$ mention 7 , and 204 give 9 in the list of digits they find hard to handle correctly.

In 1905 in Budapest, Ranschburg (97) tested I 53 children, to whom he gave 65 tests, 20 each in Addition and Subtraction, $\mathrm{I}_{5}$ in Multiplication, and Io in Division, in an attempt to determine which fundamental operation is the most difficult to school children. If we consider accuracy alone, his order, placing the easiest first, is: Addition, Multiplication, Subtraction and Division; but if they are arranged according to speed they are: Multiplication, Addition, Division and Subtraction. If both speed and accuracy be combined the order is: Multiplication, $68.75 \%$; Addition, $60.25 \%$; Division, $50.65 \%$; and Subtraction, $46.82 \%$.

Manner of Adding.-Arnett (5, 327ff) tested eight adults in their habits of adding, using I5 columns of 27 figures each. He had them add for thirty minutes, rest a few minutes and then add for thirty minutes more. Nearly 200 columns were added. It was found that some of the subjects employed straight addition, following the columns and making as many additions as there were intervals between figures, while others used combinations of digits. Out of a possible 
use of 840 combinations one announced 840 results, while another gave only $5 \mathrm{I} 9$ results for a possible 810 , having made I7 I combinations of two figures and 43 combinations of three figures each.

Cole gave three tests to 35 persons selected at random to determine their habits of adding upward and downward. The first test consisted of 20 columns of 40 figures each, the subjects adding the odd columns upward and the even ones downward. The downward adding required $15.3 \%$ more time than the upward adding, but there were fewer errors in it,$54 \%$ of the errors being made in the upward and $46 \%$ in the downward adding. The second test consisted of ro columns, identical for the upward and the downward adding, and a third tested the reading of numbers from left to right and from right to left in a horizontal line. It was found that the established habit of adding upward gave more speed but resulted in greater liability to error. In the reading of numbers the average time from left to right was 34.4 seconds with 62 errors, while the reading to the left averaged 37.I seconds with a total of 36 errors. The usual reading habit afforded greater speed to the right, but the additional attention that was demanded in the reversed reading resulted in a higher accuracy $(23,83 \mathrm{ff})$.

Socialization of Arithmetic.-Paine reports a recent experiment in Boston with some sixth-grade children who were slow and indolent in Arithmetic, but not mentally defective. They were chronic "failers" and were particularly deficient in Arithmetic. A " grocery store" was fitted out for them with enough of the real supplies to make the experiment more than symbolic. It was found that the children took on new life not only in Arithmetic but in their Language work as well. The results in Arithmetic are given as follows:

I. Increased accuracy and speed in computations.

2. Confidence was established in independent solution of problems. lems.

3. A good drill was afforded in making up original prob-

4.Some valuable training was gained in business methods.

Dooley (37) also reports some interesting work in the successful motivation of Arithmetic in the Massachusetts Industrial School.

The Wording of Problems.-The effect upon results occasioned by a change in the wording of problems is reported by Phillips $(95,268)$ in the case of 224 teachers or those preparing to teach. When 40 problems involving Gain or 
Loss, expressed in common fractions, was given them $81.6 \%$ of them solved all correctly while the others averaged 5 problems missed. Later the same problems were given to 212 of the same group, with a change only in the wording from fractions to per cent and $62 \%$ solved all correctly, while the others averaged 3 missed. During the past year Courtis (3I, 4) turned his attention to the question of the wording of problems. He was able to construct twenty-one varieties of problems, based upon a single situation, by changing the form of the question and the relative position of the phrases employed, and his tests showed that one of these problems, measured by the errors made by children in solving them, was nineteen times as difficult as another. That the mere rearrangement of the words and phrases in problems causes such wide difference in results should have careful consideration from both authors of Arithmetics and teachers of that subject.

Correlation of Abilities in Arithmetic.-Lobsien (73) concludes upon some experimental studies of arithmetical abilities with the following:

I. There is no correlation between ability to remember number images visually and the ability to write numbers.

2. The greater the ability for solving problems in the head, the weaker is the memory of numbers gained through the eye.

3. The highest correlation exists between acoustic numbermemory and ability to write numbers.

4. The good head-reckoner generally performs written work well, and vice versa.

5. Acoustic memory of numbers and ability to perform operations well have a smaller correlation.

Stone $(I I 7,43)$ believes that ability in any fundamental, with the exception of Addition, implies ability in an equal degree in the other fundamentals, nearly, and he found that many factors influence individual abilities. In the extensive tests in the New York City schools, Courtis reports $(30,79)$ that speed and accuracy have no correlation and (p. 84) "it was found that a child with good reasoning ability did not make mistakes in the abstract work." So far as his analysis of the results goes, accuracy is dependent upon reasoning and simple reasoning is directly related to ability in abstract work, high scores in "test 6" (a simple reasoning test) being associated with high scores in "test 7 " (a test in the fundamentals).

$U p$ to a certain critical point there appears to be a definite correlation between a good knowledge of the tables and ability to work speedily in the abstract examples, and a lower corre- 
lation with accuracy. The curves given by Courtis for the 13,629 boys and the 13,542 girls agree quite closely. The evidence which he submits warrants the deduction that, in general, a knowledge of the tables makes for speed and accuracy up to a certain point, beyond which other factors play such an important part that further knowledge is of no benefit $(92-96)$.

Winch (137) tested four schools in 1909 and one in I9Io in London, and reports his findings on this question, as the writer has gathered them together, as follows:

TABLE B

Correlation Tests in London Schools

\begin{tabular}{|c|c|c|c|c|c|}
\hline Tests & Grade & $\begin{array}{c}\text { Number } \\
\text { of } \\
\text { pupils }\end{array}$ & $\begin{array}{l}\text { Average } \\
\text { age }\end{array}$ & $\begin{array}{c}\text { Correlation } \\
\text { between } \\
\text { accuracy } \\
\text { and } \\
\text { reasoning }\end{array}$ & Effect of practice \\
\hline 1 & 7 and 8 & 32 girls & 13 & .68 & $\begin{array}{c}\text { Improvement. No "transfer" } \\
\text { was observed }\end{array}$ \\
\hline 2 & 3 & 43 girls & 10 & .79 & Accuracy gained \\
\hline 3 & 4 & 38 girls & 10.5 & .69 & $21 \%$ gain in accuracy \\
\hline 4 & 4 & 35 boys & 10 & .85 & $20 \%$ gain in accuracy \\
\hline 5 & 4 & 72 boys & 10.25 & .736 & $40 \%$ gain in accuracy \\
\hline
\end{tabular}

From his series of tests it appears that he found accuracy in computation to accompany good reasoning ability, but improvement in computation did not affect perceptibly accuracy in reasoning. Starch (II4, 3IO) gave special attention to the question of transfer of training in his investigations, and concludes :

"The improvement in the end was due to the identical elements acquired in the training series and directly utilized in the other arithmetical operations."

Comparison of Adults and Children.-Freeman (40a) sought in some experiments with $\mathrm{I} 4$ adults and $\mathrm{I}_{4}$ children, ranging in age between 6 and 14 years, to determine, if possible, how children differ from adults in the elementary scope of attention, and also what differences there are in the number of objects which may be grasped in a single act of attention by adults and children. He used spots of light thrown upon a screen as stimuli, and varied the time exposure from .018 to .040 of a second for the adults to more than a second for some of the children. He found the range of attention 
of adults and children to be nearer together than is generally supposed (p. 309). In adults he thinks the range may average 6 , although his observers varied from 4 to 7 , while children between 12 and I4 years of age will average 5 and younger children, 4 (p. 309). He gave 1,806 exposures to his adults, while Nanu gave only 100, and he also figured out very carefully the optimum distance at which to place his observers from the screen. For these reasons he thinks his results are better. Nanu found with her observers a decided tendency to underestimate the number of spots shown; only I of her 5 observers overestimated the number, while II of the I4 sitting for Freeman overestimated them. He reports one pure analytic type, four mixed types with strong analytic inclination, two mixed with inclination to the synthetic type, and seven of the pure mixed variety. He differs strikingly from the findings of Nanu, who reported that she found the synthetic thinkers always inclined to underestimate the numbers and the analytic type to overestimate them. Of Freeman's observers, the three who underestimated the numbers showed no tendency toward synthetic thinking, and the two who were at all inclined to synthesis overestimated the spots, -one in $94 \%$ of the erroneous judgments, and the other in $86 \%$ of the cases,-while four of the five who gave evidence of analytic thought underestimated them.

Some of the introspections seemed to show that the observers could image the groups of objects and describe them without having a grasp of the correct number, and he concludes that the number name is not essential to a comprehension of a group of objects. "Neither the word nor the name is necessary for the number-concept."

In his experiments with children he found less satisfactory results, as they were unable to give reliable introspections and only a small number of children of any age was used. Of the I4, two were 6 years of age; two were 7 ; two were 8; two were I0; four, I2; one, I3; and one, I4. As these were scattered through six of the eight grades, with no representative in the fourth and sixth grades, it gives small results for each grade. These children had been taught numbers upon the Russian reckoning-machine, so they were not entirely in new experiences. He found it necessary to exclude from his final results the four younger children's reactions, as they were unreliable. Of the remaining ro, he made two groups of 5 each according to ages. The 5 children between 8 and Io years of age showed marked differences from the 5 who were 12 to I4 years old, while the older group resembled very much the adults, both in range of attention and in its behavior. 

that:

As a general result of his experiments Freeman concludes

(I) Children as a rule comprehend a number of objects less correctly than adults.

(2) Children prefer a horizontal arrangement of objects to be seen.

(3) Children show a more rapid decline in correct answers as the number of objects is increased.

(4) The range of attention in children is from I to 2 less than in adults.

(5) Children underestimate more frequently than adults.

(6) Definite arrangements in groups is less favorable for children than for adults.

(7) Attention in young children is very irregular.

(8) No correlation was found between school-talents and correct answers.

(9) Groups of 5 were better for the children and groups of 4 for adults. This last finding agrees with the contention of Lay that the quadrate form is the best; but Freeman finds it only true for adults, rather than for school-children.

It must be confessed that we do not yet have adequate results to justify any conclusions upon the perception of simultaneously presented objects as a basis for early number training. Too few observers have been used so far.

From such experiments as those of Freeman, one may be led to infer that the basis for the difficulties encountered by children and adults in mastering the multiplication table lies in the inability to handle numbers in groups of more than 5 or 6 readily. To master the table of 7's or 8's or 9's, one has to group the numbers in bundles of 7 , or 8 or 9 . The pupil usually finds the numbers below 6 rather easy in comparison with numbers between 6 and ro. To say the 9's, one has to group the numbers up to 90 in bunches of 9's, and the attention has to pass rapidly over the groups if the learner is at all visually minded.

Individual Differences.-There is to be seen from the various experiments reported a very wide divergence in number ability among school children. These differences are shown in the aversion of some to the subject as a school topic, while others choose it as their favorite branch. This is often caused by wrong motivation at some previous time, or to attitudes of parents toward the subject, or to poor teaching in a lower grade, in the case of those who dislike it; and to home encouragement, proper motivation, or good teaching, or per- 
haps, to all these influences combined in the case of those who prefer it. Frequently, it has been found that differences in habits of thinking cause variations in school interest in Arithmetic. No doubt, the varying degrees of interest may sometimes lie far back of school experience, in the child's opportunities to satisfy his inclinations for number in the nursery. Provisions that are made for the natural growth in number in young children in various materials afforded in the home, coupled with an active interest on the part of the mother, often determines the future bent of the child. While no other subject has been as much taught in the modern school, it is equally true that in no other subject has there been so much bad teaching. So to-day, partly through imperfect teaching and a variety of pre-school inclinations, we find in the school grades children of almost every degree of advancement in the same grade. Some in the first or second grades have as good ability in numbers as others in the sixth, seventh, or eighth grades.

Sex Differences.-In addition to the effect of puberty already cited from Voigt, a number of observations have been recorded upon the differences in arithmetical abilities dependent upon sex. Ballard $(9,18)$ says that in a series of tests in the London schools the girls showed better mechanical skill in the solutions, but the boys did the problems better, and "on the whole the boys were considerably ahead of the girls." Phillips $(93,163)$ tested 69 pupils in the Granite Falls, Minn., schools from March to May, I9I2, and found in the progress made in drill work that "the girls did better than the boys in tests in fundamentals" and the boys "did better work in reasoning," while the boys made a greater gain between the tests than did the girls, their gain being about $24 \%$ over that of the girls. In his extensive tests in New York City, Courtis (30, I36) found also that "the girls exceeded the boys in the speed tests in multiplication, but they fell below them in accuracy in reasoning." From a comparison of all the scores made by the boys and the girls it is seen that the girls excel the boys in mechanical work in the fundamentals and the boys excel in simple reasoning. He concludes: "Differences between the abilities there undoubtedly are, but whether due to sex or to environmental influences the differences are too slight to be of any significance so far as present knowledge goes." Smith (I09) reports on 3,869 students tested in the Normal School at Cortlandt, N. Y., as follows:

Of 1,265 men put on examination, $58.7 \%$ passed with an average of $84.1 \%$. 
Of 2,603 women put on examination, $50.6 \%$ passed with an average of $83.4 \%$.

$\mathrm{He}$ also gives the records of 1,462 men and 1,564 women at Ypsilanti, Mich., which show practically no distinctions are to be made in Arithmetic on account of sex.

The Rice Tests.-In the autumn of I902, Dr. J. M. Rice gave a test of eight problems to 6,000 school children in seven cities $(98,100)$. The children were chosen from grades four to eight inclusive. In all, 18 schools, some in the slum districts, some in the better districts and some in aristocratic neighborhoods, were included. He studied the effect of home environment, size of classes, total time per day given to Arithmetic, average age of pupils, forenoon and afternoon periods of recitation, methods of instruction, teaching ability of the instructors, and concluded that none of these was the determining factor in securing good results in the subject. Rather surprisingly he puts the whole responsibility ultimately upon the supervision. "This means (p. I36) in other words that the controlling factor in the accomplishment of results is to be found in the systems of examinations employed, some systems leading to better results than others." He found wide variations in the upper grades, mechanical errors increasing in them, with a decided deterioration in the 5 th and 6th grades. Cities usually ranked with their individual schools; that is, good work in one school usually signified good work throughout the whole city.

The Stone Tests.-Dr. C. W. Stone (II7) gives detailed data from 26 school systems scattered well over the United States and comprising tests in Arithmetic which he personally gave to 152 classes of pupils in the $6 \mathrm{~A}$ grade. Of the systems tested, 6 were located in New England, I I in the Middle East, and 9 in the Middle West. The tests were given under controlled conditions, and covered the fundamental operations and the children's ability to reason upon the solutions. With 6,000 sets of papers to study he draws the following conclusions :

I. The net result of arithmetic work in the first six years is several products, rather than $a$ product. The study called Arithmetic makes demand upon a plurality of abilities (p. 43).

2. There is a great variability in the products of different systems, and greater still among individuals in any system. The variability among boys does not appreciably differ from that among girls. 
3. The possession of a certain amount of ability by a system is a better guarantee of the same amount of another ability than the possession of a certain amount of ability by an individual is that he will have the same amount of another ability.

He agrees with Rice upon the effect of good supervision, but found different results on the tests in reasoning (p. 45). He had the courses in Arithmetic in these 26 systems rated for him by 21 professors and graduate students in education (p. $7 \mathrm{I}$ ) and compares the results of his tests with these ratings. He says:

"The situation seems to be that the course of study is not at present the factor that it ought to be in producing abilities. In certain systems it is evidently working well, but in others there is a wide-spread disparagement between excellence in abilities and excellence in the course of study." "The course of study may be the most important single factor but it does not produce abilities unless taught. The other essential features for successful teaching are teachers and children of usual abilities, a reasonable time allotment, intelligent supervision and adequate measurement of results by tests (p. 9r).

The Courtis Standard Tests.-Following immediately upon the results obtained by Stone, Dr. S. A. Courtis began by giving the Stone tests to 3 I 7 girls in the Liggett school at Detroit, in 1908 and 1909 . These girls were scattered through the grades from the $3^{\text {rd }}$ to the $13^{\text {th }}$. Using his results as a basis, in September, 1909, he devised a new set of tests covering speed in each of the four fundamental operations, one in copying figures, two in reasoning and one general test in all four fundamentals. Under controlled conditions these were given to the same school in September, I909, and in June, I9I0. Among other results he found as did Rice that the 6th grade was a "notoriously difficult" one, although it had ranked high as a 5 th grade the previous year $(29, \mathrm{p}$. 361 ).

From this beginning, Courtis came to believe that a uniform standard test could be devised, so he sought during the school year, I9IO-II, to establish such a standard. He gathered papers from near 9,000 children in from 60 to 70 schools scattered in Io states. These children had been given his 8 tests and a "standard" table was constructed from the results, which is given here after corrections have been made in it from later facts gathered altogether from 66,837 children and revised to August, ror3.

From Table $\mathrm{C}$ it will be seen that a 6th grade child should be able to give correctly 50 combinations in addition of digits, 38 in subtraction, 37 in multiplication and division, 
and copy figures at the rate of 92 per minute. The scores from grades 3 to 8 inclusive are revised to suit the figures from 66,837 tests, while the others, I understand, are those made out from the first studies gathered from ig cities.

TABLE C

Courtis Standard Scores, Showing What a Child in Each Grade Should be ABLE to Accomplish in ONE MiNuTe

\begin{tabular}{c|c|c|c|c|c}
\hline \hline Grade & $\begin{array}{c}\text { Number of } \\
\text { simple } \\
\text { additions }\end{array}$ & $\begin{array}{c}\text { Number of } \\
\text { simple } \\
\text { subtractions }\end{array}$ & $\begin{array}{c}\text { Number of } \\
\text { simple } \\
\text { multiplications }\end{array}$ & $\begin{array}{c}\text { Number of } \\
\text { simple } \\
\text { divisions }\end{array}$ & $\begin{array}{c}\text { Number of } \\
\text { figures } \\
\text { copied }\end{array}$ \\
\hline 1 & $(6)$ & $\ldots \ldots \ldots$ & $\ldots \ldots$ & $(29)$ \\
\hline 2 & $(21)$ & $(12)$ & $(10)$ & $(12)$ & $(51)$ \\
\hline 3 & 26 & 19 & 16 & 16 & 63 \\
\hline 4 & 34 & 25 & 23 & 23 & 75 \\
\hline 5 & 42 & 31 & 30 & 30 & 84 \\
\hline 6 & 50 & 38 & 37 & 37 & 92 \\
\hline 7 & 58 & 44 & 41 & 44 & 100 \\
\hline 8 & 63 & 49 & 45 & 49 & 108 \\
\hline 9 & $(65)$ & $(50)$ & $(50)$ & $(50)$ & $(120)$ \\
\hline 10 & $(57)$ & $(45)$ & $(43)$ & $(46)$ & $(112)$ \\
\hline 11 & $(59)$ & $(47)$ & $(44)$ & $(48)$ & $(114)$ \\
\hline 12 & $(61)$ & $(48)$ & $(44)$ & $(49)$ & $(112)$ \\
\hline 13 & $(71)$ & $(56)$ & $(50)$ & $(56)$ & $(116)$ \\
\hline 14 & $(74)$ & $(51)$ & $(58)$ & $(59)$ & $(124)$ \\
\hline
\end{tabular}

The New York City Tests.-From March I5 to April 26, I9I2, Courtis applied his tests in New York City to a list of 33,350 pupils, representing a school register of 40,000 pupils, or about one-tenth of the city school population from the $4^{\text {th }}$ up to the 8 th grade. Representative schools were selected in various parts of the city; 2I schools furnishing 380 classes with 12,147 pupils, were in Manhattan borough; 9 schools, with I48 classes and 4,488 pupils, were in the Bronx; I8 schools, with 3 I 5 classes and 10,243 pupils, were in Brooklyn; 2 schools with 23 classes and 646 pupils were in Richmond borough; and 2 schools with 37 classes and I,I45 pupils in Queens. From these, 28,669 complete returns were received, but only 27,I7I were tabulated because of apparent irregularities in the remainder. Courtis went to New York and personally took charge of the tests at the request of the "Hanus Committee in Charge of Educational 
Aspects of School Inquiry." His purpose was to determine, if possible, the following:

I. The standard of achievement in fundamental operations with whole numbers, and in simple reasoning.

2. The relative achievement of the schools tested, as measured by standards.

3. The relative achievement of grades and individuals, as measured by standards, so far as is necessary to indicate to teachers, principals, and superintendents how such knowledge could be used to make their work more efficient.

4. The relative achievement of New York City schools as a whole, as measured by standards derived from tests in other cities.

In the following table will be given the score of the various grades in each one of the eight tests used and at the same time the highest score made by any pupil, with some other data that may assist in one's understanding the gross results of the experimental study. It is not possible for us to enter upon any comprehensive consideration of the minor details reported by Courtis in his I58-page booklet. A few findings have already been mentioned and a few others remain to be noted after the table is studied.

TABLE D

Correct Score Averages Made by the Different Grades in the NEW YORK CITY SCHOOLS

\begin{tabular}{|c|c|c|c|c|c|c|c|c|c|c|c|}
\hline \multicolumn{3}{|c|}{ Grades tested................ } & 4 th & 5 th & 6 th & 7 th & 8th & 9th & 10 th & 11 th & 12th \\
\hline \multicolumn{3}{|c|}{ Number of pupils in each........ } & 5396 & 5386 & 5670 & 4771 & 4502 & 440 & 257 & 179 & 120 \\
\hline \multicolumn{3}{|c|}{ Average age of the pupils........ } & 10.5 & 11.3 & 12.4 & 13.9 & 14.6 & & & & \\
\hline No. & Kind of test & $\begin{array}{l}\text { Max. } \\
\text { Score }\end{array}$ & & & & & & & & & \\
\hline 1 & Addition, - speed... & 125 & 41.9 & 50.2 & 56.9 & 62.2 & 69.5 & 71.6 & 71.7 & 73.9 & 74.2 \\
\hline 2 & Subtraction, - speed & 125 & 29.5 & 36.8 & 41 & 45.8 & 52.2 & 52.2 & 55.3 & 55.2 & 54.1 \\
\hline 3 & $\begin{array}{l}\text { Multiplication, - } \\
\text { speed............... }\end{array}$ & 125 & 28.7 & 35 & 38.3 & 40.9 & 45.8 & 46.5 & 46.8 & 48.6 & 46.6 \\
\hline 4 & Division, 一 speed ... & 125 & 26.6 & 34.7 & 39.7 & 44.6 & 50.9 & 52.5 & 52.7 & 54.2 & 55 \\
\hline 5 & $\begin{array}{l}\text { Copying figures,-- } \\
\text { speed............ }\end{array}$ & 205 & 75.4 & 85.5 & 92.5 & 100 & 106.8 & 98.8 & 104.5 & 109.4 & 105.6 \\
\hline 6 & $\begin{array}{l}\text { Reasoning, }- \\
\text { one step.......... }\end{array}$ & 16 & 1.8 & 2.3 & 3 & 3.7 & 4.4 & 5.1 & 5.1 & 5.1 & 5.7 \\
\hline 7 & Fundamentals...... & 19 & 4.2 & 5.8 & 7 & 8.5 & 10.1 & 10.9 & 11.5 & 10.5 & 11 \\
\hline 8 & $\begin{array}{l}\text { Reasoning, }- \\
\text { two steps... }\end{array}$ & 8 & .7 & .9 & 1.3 & 1.7 & 2.1 & 2.5 & 2.6 & 2.7 & 2.7 \\
\hline & & & & & & & & & & & \\
\hline
\end{tabular}


It must be borne in mind that the Courtis tests are exactly the same for all the grades and that he holds that a score of forty answers per minute means double the ability that gives only twenty per minute (p. I7), and to change from 20 to 25 answers corresponds to a change from 40 to 45 per minute. The errors that were shown in the papers he classifies as follows:

I. Carelessness in bringing down the wrong figure in division or placing partial products in multiplication under the wrong figure, $12.5 \%$.

2. Copying incorrectly, reversing figures, as 639 for $693,8 \%$.

3. In fundamental combinations, $50 \%$.

4. Scattered, such as errors in carrying, etc., all the rest.

Many errors were found in handling zero. It is worthy of mention here that in Columbia University, in the summer of I9IO, 4I adult graduate students, teachers and superintendents were tested and 18 made 104 mistakes in zero combinations particularly when zero occurred in the multiplier.

$\mathrm{He}$ found in the New York schools, as has been found wherever tests have been applied, that the work in fundamentals is very low both in speed and in accuracy in computation and simple reasoning. The critical period for the mastery of these fundamentals seems to lie down in the lower grades. In the introduction to the Courtis Report, Dr. Hanus calls attention to the low degree of efficiency in the schools and says: "Children of every level of ability are found in every grade and differences between individuals greatly exceed the difference between grades." For this reason the fundamentals should be adapted to the individuals and they should be taught in the light of individual capabilities. "This condition is universal and is not due to lack of effort or other conditions that could be easily removed, but to a neglect of one basic factor,- the difference in the powers and capabilities of children," ( $p .76$ ), because children are already at school entrance highly specialized in their mental habits. Courtis thinks (p. I 30) that a more simple and practical course in Arithmetic, based directly upon the social needs of the children, would influence for good a greater number of both children and teachers.

The Boston Tests.-The same eight tests were given by Courtis to 29 of the schools in Boston, in October, I9I2, and again in March, I9I3. More than 500 classes and about 25,000 children were included. These tests were designed to determine the following facts: 
I. The standard of arithmetical work in the Boston schools, and their comparative standing with other schools already tested.

2. The nature and degree of change produced by six months regular work in Arithmetic.

3. The effect of certain special methods of individual instruction.

Supt. Dyer devotes only thirteen pages of his recent report $\left(3^{8}\right)$ to these tests, yet some valuable facts are disclosed:

I. Boston is lower in abstract work and higher in reasoning than New York.

2. A comparison of the tests in March with those six months earlier shows that $53 \%$ of the pupils made improvement, $30 \%$ stood still and $17 \%$ lost.

3. Four special methods were employed in the experimental study:

(a) In one group, each teacher took one period per week to work with individual pupils who seemed from the October tests to need particular strengthening upon certain points. This was continued for twelve weeks, and the group as a whole gained $14 \%$.

(b) A second group had the assistance of an able specialist, one to each school being assigned to the task of giving individual help to children sent by the regular teachers. This also ran for twelve weeks, and 2,187 children out of 3,443 received individual assistance, in 60,000 interviews lasting I 5 minutes each. The report says this method did not yield the results expected.

(c) A third group pursued regular work with no remedial help, and were used as a "control "group in measuring the others.

(d) A fourth group was formed in March, of pupils who had not taken the October tests, and they were given special daily drills on the fundamentals for ten minutes each day during the regular recitation period. In the March tests this group attempted fewer problems and examples than the others and "this method was the least effective."

A comparison of the three drilled groups with the "control" group shows that:

I. Group one, in which the regular teachers devoted one period per week to a class drill upon fundamentals, exceeded the "control" group by $8 \%$ in accuracy. 
2. Group two, in which a special teacher gave individual help, exceeded it by $5 \%$.

3. Group four, in which the ten-minute drill upon fundamentals preceded the test, exceeded it by only $3 \%$.

These facts seem to emphasize the value of systematic work under the regular teacher and to discount the common practice of "cramming" for tests and examinations.

Personal Observation of the Recent Boston Tests.-On Thursday, January 8, 1914, the writer went to Boston to observe the giving of the new Courtis tests which were to be given to more than 20,000 children, beginning that day under the supervision of Miss Rose A. Carrigan, of the Boston Normal School. Three schools were selected, one mixed and one each in which the boys and girls are taught separately. Miss Carrigan had furnished me a list of all the schools to be tested each day, so I went on Thursday without her knowledge to schools of my own selection. In all, I saw the tests given to 8 rooms, 5 th, 6 th, and 7 th grades, 350 children being present and taking the tests. I saw 15 of the young lady "cadets" doing the testing at the three schools, two working together in each room. One would explain the signals to be observed while her assistant manipulated the signalbox and announced the time to start and quit. There was splendid management in handling the tests and I have no criticism to offer on the fairness of the application of the tests. The children seemed to enjoy the game and so far as I could see took no notice of my presence or that of the master who accompanied me to their room. 53 cadets were busy in these tests after being trained by Miss Carrigan for three days. Another test was given the second week in April, I9I4, but it will be several weeks before results can be known. These tests are to (I) set definite standards for each grade, (2) measure the results of each teacher's work, (3) assist in motivating the children's work, and (4) to furnish some studies in the grading.

Criticism of Standardization.-It is proper that I give some discussion upon the general proposition to attempt a "standardization" of the achievements in Arithmetic, which is, after all, only a subordinate notion of "standardization" in all studies. There appears a strong tendency to-day to try to standardize everything, products and producers alike, and educational circles seem to have been caught in the current. The trades are said to have a definite number of doors for a carpenter to hang in a day, or a specific product to be turned out, beyond which a good workman will not endeavor to go. With discriminating accuracy there are attempts to 
"standardize" in this world-movement not only Arithmetic, but also penmanship, compositions, cattle, peanuts and parents!

Courtis has selected a certain line of level from the thousands who have been tested by his method and sets these levels up as a standard for the schools everywhere. This would not seem so serious did we not find him saying (3I, I4):

"It should be noted that standards will not produce uniform products unless they are treated both as goals to be reached, and as limits not to be exceeded."

He points out that the average score, for instance, of II,059 8 th grade pupils on test No. 7 was 9.5 examples correctly done, but $38 \%$ of these pupils had been so overtrained that they exceeded this score by 10\% to 100\%. "These high scores of school children represent waste effort." "When standard ability has been attained, additional degrees of mechanical skill are products of the least importance."

While the writer is in complete sympathy with every attempt to place Pedagogy upon a sound and genuine scientific basis, he does not consent willingly to the effort to "Procrusteanize" the schools by requiring them to be measured and directed by semi-arbitrary standards. Abilities of children are too widely variant and future callings are too diverse for us to agree that each child in the great public school system shall be moulded into the same set form in Arithmetic, or, indeed, in any school subject, by accepting standards which are to be reached but not exceeded. The present movement is awakening much interest among the school public and must result in good. Its chief temptation lies in the extravagant application of some of its obviously useful features until the practical educator will be led to reject even what help it should be able to offer.

The selection of a semi-arbitrary standard in Arithmetic has gone no farther than the four fundamental operations and simple problems in reasoning, and has not approached fractions, denominate numbers, ratio, percentage, mensuration,-yet to me it seems much like taking the average peracre corn crop of the country, or more correctly, of a few sections, and setting this up as a "standard" to be reached but not exceeded by farmers everywhere! Boys' Corn Clubs have shown the corn raisers the fallacy of taking "averages" as standards. It is a little similar in educational work. As land differs in fertility, so children differ in Begabungen or talents. As farmers differ in their methods of cultivation, so parents and teachers differ in Erziehung. We may have to leave the Begabungen with the biologist and the eugenist; but with more fertile methods of instruction, with a more socialized curriculum, it is possible for these experimental 
studies to become "stepping-stones" upon which we may rise to higher things. At all events we should recognize and respect, nay more, develop and encourage the individuality in every child.

\section{TABLE E}

Distribution of Arithmetical Topics in the Grades in american Cities* All figures are to be read as percentages

\begin{tabular}{|c|c|c|c|c|c|c|c|c|c|}
\hline Topic & $\left|\begin{array}{c}\text { Cities } \\
\text { having } \\
\text { it }\end{array}\right|$ & 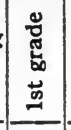 & 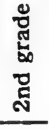 & 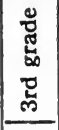 & 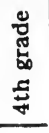 & 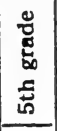 & 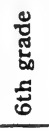 & 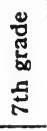 & 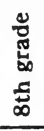 \\
\hline Numbers introduced..$\ldots \ldots \ldots \ldots$ & all & 71.5 & 22 & 6.5 & $\cdots$ & .. & . & $\cdots$ & .. \\
\hline Fundamentals completed........... & all & $\ldots$ & $\cdots$ & 5 & 78 & 17 & .. & .. & . \\
\hline Common fractions begun. . . . . . . . & all & 14 & 21 & 17 & 21 & 27 & $\cdots$ & . & $\cdots$ \\
\hline Fractions emphasized.............. & all & .. & $\cdots$ & 2 & 10 & 63 & 23 & 2 & . \\
\hline Decimal fractions taught............. & all & .. & .. & . & 9 & 32 & 40 & 13 & 6 \\
\hline Ratio.............. & all & . & .. & . & 5 & 8 & 11 & 20 & 56 \\
\hline Percentage, general cases........... & all & $\cdots$ & $\cdots$ & $\cdots$ & 5 & 30 & 45 & 20 & $\cdots$ \\
\hline Simple interest................. & all & $\cdots$ & $\cdots$ & $\cdots$ & .. & 5 & 20 & 45 & 30 \\
\hline Compound interest................ & 64.7 & $\cdots$ & $\cdots$ & $\cdots$ & $\cdots$ & . & 5 & 40 & 55 \\
\hline Commission...$\ldots \ldots \ldots \ldots \ldots \ldots$ & all & .. & . & .. & $\cdots$ & 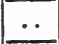 & 15 & 55 & 30 \\
\hline Commercial discount.............. & all & $\because$ & . & . & $\cdots$ & . & 10 & 50 & 40 \\
\hline Bank discount..................... & all & .. & .. & .. & .. & . & . & 40 & 60 \\
\hline Exchange...................... & 42.8 & $\cdots$ & $\cdots$ & $\cdots$ & $\cdots$ & $\cdots$ & $\cdots$ & 23 & 77 \\
\hline Stocks and bonds................ & 71.4 & $\cdots$ & $\cdots$ & $\therefore$ & $\cdots$ & $\cdots$ & $\cdots$ & 23 & 77 \\
\hline Partial payments............... & 60.7 & $\cdots$ & $\cdots$ & $\cdots$ & $\cdots$ & $\ldots$ & 5 & 20 & 75 \\
\hline Partnership................... & 57.1 & $\cdots$ & $\cdots$ & $\cdots$ & $\cdots$ & $\cdots$ & $\therefore$ & 28 & 72 \\
\hline Simple proportion................. & all & $\cdots$ & $\cdots$ & $\cdots$ & $\cdots$ & $\cdots$ & 12 & 21 & 67 \\
\hline Compound proportion............ & 42.8 & $\cdots$ & $\cdots$ & $\therefore$ & $\therefore$ & $\cdots$ & . & 24 & 76 \\
\hline Mensuration, - of plane figures...... & all & . & . & . & 10 & 12 & 20 & 30 & 28 \\
\hline Mensuration, - of solids.............. & all & $\cdots$ & $\cdots$ & $\cdots$ & . & 12 & 18 & 25 & 45 \\
\hline 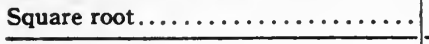 & all & .. & $\ldots$ & .. & .. & $\therefore$ & . & 15 & 85 \\
\hline 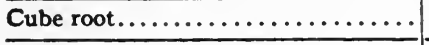 & 28.5 & $\cdots$ & $\cdots$ & $\cdots$ & $\cdots$ & $\cdots$ & $\cdots$ & 25 & 75 \\
\hline Factoring $\ldots \ldots \ldots \ldots \ldots \ldots \ldots \ldots$ & all & $\cdots$ & $\cdots$ & $\cdots$ & 12 & 33 & 25 & 18 & 12 \\
\hline Least common multiple............ & all & .. & . & .. & 15 & 37 & 34 & 10 & 4 \\
\hline Greatest common divisor.......... & all & . & $\therefore$ & 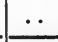 & 12 & 37 & 37 & 10 & 4 \\
\hline Metric system... & 35.7 & .. & . & . & .. & .. & .. & 28 & 72 \\
\hline
\end{tabular}

- In the above table the distribution of the topics is given for 28 American cities reporting to the American Committee of the International Commission on the Teach. ing of Mathematics, and published in the U. S. Bureau of Education Bulletin No. 13, 1911, pp. 16-65, 75-78. These cities represent about one-tenth of the scholastic population in the United States. 
TABLE F

ImPORTANT Facts ABout the Experimental Studies in ARIthmetic

\begin{tabular}{|c|c|c|c|c|}
\hline Investigator & Country & Subjects & Date* & Purpose of experiments \\
\hline 1. Phillips, D. E. & America & 260 children & 1897 & Popularity of arithmetic \\
\hline 2. Lewis........ & England & 8,000 & 1913 & “ \\
\hline 3. Messenger.... & America & 6 adults & 1903 & Kinds of thinkers \\
\hline 4. Nanu......... & Germany & “ & 1904 & $“$ \\
\hline 5. Freeman..... & “ & 14 children & 1910 & $\begin{array}{l}\text { Differences in adults and chil- } \\
\text { dren }\end{array}$ \\
\hline 6. Lobsien...... & “ & $\ldots \ldots \ldots \ldots$ & 1913 & Sex differences \\
\hline 7. Ballard........ & England & ............. & 1912 & “ \\
\hline 8. Smith........ & America & 3,869 adults & 1895 & “ \\
\hline 9. $\quad “ \quad \ldots \ldots \ldots$ & “ & 9,307 & 1895 & “ \\
\hline 10. Phillips, F. M. & $“$ & 69 children & 1913 & “ \\
\hline 11. Courtis....... & “ & 27,171 & 1912 & $“$ \\
\hline 12. Voigt........ & Germany & $\ldots \ldots \ldots \ldots \ldots$ & 1912 & “ \\
\hline 13. Brown....... & America & 51 children & 1911 & Effect of drill \\
\hline $14 . \quad " \quad \ldots \ldots \ldots$ & “ & 222 & 1912 & “ \\
\hline 15. Phillips, F. M. & “ & 69 & 1913 & $"$ \\
\hline 16. Starch....... & “ & 15 adults & 1911 & “ \\
\hline 17. Thorndike.... & “ & 33 & 1908 & “ \\
\hline $\begin{array}{lll}18 . & \cdots & \ldots \\
\end{array}$ & “ & 19 & 1910 & “ \\
\hline $\begin{array}{l}19 . \text { Donovan and } \\
\text { Thorndike... } \\
\end{array}$ & “ & 29 children & 1913 & “ \\
\hline 20. Kirby......... & “ & 1,338 & 1912 & $“$ \\
\hline 21. Hahn........ & “ & 192 & 1913 & “ \\
\hline 22. Wells........ & “ & 10 adults & 1910 & “ \\
\hline 23. Whitley...... & “ & $9 \quad “$ & 1912 & “ \\
\hline 24. Jeffrey........ & Scotland & 18 children & 1912 & “ \\
\hline 25. Kirby.......... & America & 1,338 & 1912 & Effect of long and short drills \\
\hline 26. Whitley....... & “ & 9 adults & 1912 & “ \\
\hline 27. Thorndike.... & “ & 16 & 1913 & $“$ \\
\hline 28. Wells........ & “ & $6 " 4$ & 1912 & Permanency of improvement \\
\hline 29. Kirby......... & “ & 258 children & 1912 & $“$ \\
\hline 30. Brown........ & “ & 51 & 1911 & “ \\
\hline 31. Ranschburg .. & Hungary & 153 & 1909 & $\begin{array}{l}\text { Relative difficulty of fundamen- } \\
\text { tals }\end{array}$ \\
\hline 32. Phillips, D. E. & America & 440 & 1897 & $\begin{array}{l}\text { Relative difficulty of fundamen- } \\
\text { tals }\end{array}$ \\
\hline
\end{tabular}

* The dates given are those for the year in which the experiments were made when these were obtainable; otherwise, for the year when the results were published. 
TABLE F-Continued

Important Facts About the Experimental Studies in Arithmetic

\begin{tabular}{|c|c|c|c|c|c|}
\hline Investigator & Country & \multicolumn{2}{|c|}{ Subjects } & \multirow{2}{*}{$\frac{\text { Date* }}{1912}$} & \multirow{2}{*}{$\frac{\text { Purpose of experiments }}{\frac{\text { Relative difficulty of fundamen- }}{\text { tals }}}$} \\
\hline 33. Phelps....... & “ & 270 & “ & & \\
\hline 34. Cole......... & $\because$ & \multicolumn{2}{|c|}{35 adults } & 1912 & Adding upward and downward \\
\hline 35. Arnett....... & 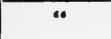 & 8 & “ & 1905 & Manner of adding \\
\hline 36. Paine........ & $“$ & \multicolumn{2}{|c|}{12 children } & 1913 & \multirow{2}{*}{$\begin{array}{l}\text { Motivationthrough store-kee } \\
\text { Effect of change in wording }\end{array}$} \\
\hline 37. Phillips, D. E. & “ & 224 & $“$ & 1897 & \\
\hline 38. Courtis........ & “ & 317 & “ & 1909 & $\begin{array}{lll} & \text { " }\end{array}$ \\
\hline 39. Winch........ & England & \multicolumn{2}{|c|}{32 girls } & 1909 & $\begin{array}{l}\text { Correlation and transfer of abil } \\
\text { ities }\end{array}$ \\
\hline 40. “ $\quad \ldots \ldots \ldots$ & “ & 43 & “ & 1909 & $\begin{array}{l}\text { Correlation and transfer of abil } \\
\text { ities }\end{array}$ \\
\hline 41. “ $\quad \ldots . . .$. & “ & 38 & “ & 1909 & $\begin{array}{l}\text { Correlation and transfer of abil- } \\
\text { ties }\end{array}$ \\
\hline 42. “ $\quad \ldots \ldots \ldots$ & “ & \multicolumn{2}{|c|}{35 boys } & 1910 & $\begin{array}{l}\text { Correlation and transfer of abil- } \\
\text { ties }\end{array}$ \\
\hline $43 . \quad “ \quad \ldots \ldots \ldots$ & “ & 72 & “ & 1910 & $\begin{array}{l}\text { Correlation and transfer of abil- } \\
\text { ties }\end{array}$ \\
\hline 44. Rice........ & America & \multicolumn{2}{|c|}{6.000 children } & 1902 & Comparative results of schools \\
\hline 45. Stone........ & “ & 6,000 & “ & 1908 & Results of six years' work \\
\hline 46. Courtis........ & “ & 317 & 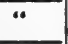 & 1909 & Speed, accuracy and reasoning \\
\hline$\ldots \ldots$ & $“$ & 9.000 & $\because$ & 1911 & Standardization of aims \\
\hline ....... & “ & 27,171 & $“$ & 1912 & Abilities as related to standards \\
\hline ....... & $"$ & 25,000 & “ & 1913 & $“$ \\
\hline 50. Carrigan..... & “ & 20.646 & “ & 1914 & “. \\
\hline
\end{tabular}

* The dates given are those for the year in which the experiments were made when these were obtainable; otherwise, for the year when the results were published.

\section{Discussion and Pedagogical Deductions}

Several facts seem to stand out quite clearly in these experimental studies. Some of the more prominent ones are: (I), Inadequate results are now being obtained in Arithmetic in practically all schools; (2), Courses of study, judged by experts as superior, give no better results than those judged as inferior; (3), The better educated teachers are not having more success than the less educated ones; (4), Small expenditure of time devoted to drill upon fundamentals under optimal conditions gives surprising mechanical skill, which remains fairly permanent; (5), The paradoxical situation has received no adequate and satisfactory explanation up to the present time. 
With painstaking care, Rice, in his pioneer investigations a decade ago, eliminated one by one the elements that he thought had any bearing upon the cause of such poor mastery of Arithmetic and finally left the burden upon the superintendent and the system of examinations employed in the schools. However, I believe he was far from the proper diagnosis. The whole trouble, when we come to the ultimate analysis of the case, lies in the failure of the pupils to comprehend what they pass over in Arithmetic,-they lack an orderly association of the principles of the subject, and they do not have their fundamental and hierarchical systems of mathematical habits well established. Bryan and Harter (I6a, 360) tell us that "A man is organized in spots-or rather in some spots-far more than in others. This is true structurally and functionally." "Some habits are knit together in a hierarchy."

"There are a certain number of habits which are elementary constituents of all the other habits within the hierarchy. There are habits of a higher order which, embracing the lower as elements, are themselves in turn elements of higher habits. A habit of any order, when thoroughly acquired, has physiological and, if conscious, psychological unity. The habits of lower order which are its elements tend to lose themselves in it, and it tends to lose itself in habits of higher order when it appears as an element therein."

Proficiency in Arithmetic rests pre-eminently upon a mastery of habits associated in hierarchical fashion. Here, perhaps more than in any other school subject, does a ready habitual response indicate efficiency, and as Horace Mann might say $(52 a, 236)$ : "One former is worth a hundred reformers." With our new psychology we are needing a few new canons for Arithmetic. Bryan and Harter say (16a, 375):

"Now the ability to take league steps. . . , in addition, . ' plainly depends upon the acquisition of league-stepping habits. No possible proficiency and rapidity in elementary processes will serve. The learner must come to do with one stroke of attention what now requires half a dozen, and presently in one still more inclusive stroke, what now requires thirty-six. He must - acquire a system of habits corresponding to the system of tasks. When he has done this he is master of the situation in his field. . . Finally, his whole array of habits is swiftly obedient to serve in the solution of new problems. Automatism is not genius, but it is the hands and feet of genius."

If these authors are right, then it is the first business of the teacher in Arithmetic to see that the right habits are formed from the beginning and that the fundamental habits which enter into higher ones later on shall be intelligently approached by the teacher. Certainly, no other branch of school work utilizes more the first habits in the formation 
of those that follow. The child's first experience with numbers in school should be made to assist it in his next step and the earliest drills in addition should be the steppingstones to higher functioning in the work that follows. One great fault has been that schools have sought to introduce children to the mastery of problems involving situations when the children should have been mechanizing the processes of the fundamentals. The preadolescent period in school is distinctively the psychological age for drills; it is not the period to demand either reasoning or imagination upon the part of children. Hall (52a, 3I3) says: "Puberty is the birthday of the imagination," and it is discouraging and wasteful to thrust verbal propositions upon young children, requiring them to wrestle with the interpretation of a complex situation, when they should be establishing a whole federation of hierarchies of mathematical habits, so that there will be both speed and accuracy in responses when there is need for them. We shall profit greatly if we return to the discarded oral Arithmetic, and give patient, systematic drills upon rapid adding, subtracting, multiplying and dividing, without pencil or crayon. Hundreds of examples should be announced orally by teachers in these four fundamentals, and the children taught to respond quickly. In this way the lower habits of association are formed. With proper drills there is every reason to believe that children in the sixth and seventh grades will far surpass the present status in those grades. These rapid elementary processes favor prompt fusion into the higher unitary processes, and are also favorable for prompt reactions when new emergencies arise. Since one's response to a situation depends partly upon the rate of mental and nervous processes, but "far more upon how much is included in each process," it will be seen how necessary it is to present only simple stimuli until they have been mastered. In almost any regular class in Arithmetic can be seen pupils who add, subtract, multiply and divide with great speed, while others are going along at moderate pace, and still others are laboriously struggling with the most elementary processes by means of objective helps, like the fingers. Perhaps, the rapid worker expends less energy and finishes in one-fourth the time, because his federation of habits has done his work for him, so to speak, while the other pupils have been going over the ground as if it were strange territory to them. The main habits to be drilled into the young arithmetician are: (I) rapid association of numbers in the four fundamental processes ; (2) accuracy in computations; (3) alert and keen attention to statement of examples and problems; and (4) quick application of the proper process to new situations. Teachers should 


\section{CONTRIBUTION TO THE PEDAGOGY OF ARITHMETIC}

be extremely careful to avoid arrested development in the lower order of habits,- - so often seen in children in the public schools. By starting right, and establishing the lower habits well, it is easy to follow with the proper sequence of simple habits, on up into the organization of the higher groups, or hierarchies.

If $I$ am right in placing the first burden of responsibility upon the individual teacher, there is to be an equal sharing with the authors of texts in Arithmetic. In no other subject in the curriculum does the structure of the text-book determine so largely the teacher's procedure as in Arithmetic. The majority of public school teachers follow closely the order of topics and the exact rules of treatment laid down in the book. Small change is ever made in any of the material presented. It is taken explicitly, and no adaptation is made to specific needs of classes or individual pupils.

It is also true that Arithmetic demands, more than other branches, an orderly association, not only of its fundamental facts, but even more emphatically, a related and orderly grouping of all the subsequent topics. It follows from these desiderata that the improvement in results in Arithmetic must begin far back in the treatment of the topics by the authors of series of texts for school use. We shall hardly have better accomplishments among pupils until our texts are built upon more psychological and pedagogical lines. The present books are characterized by unnecessary and indefensible separation of genetically related topics that are given to the children as wholly new and unrelated; and as a consequence the memory is overworked with rules, formulas and model solutions, and there is no systematic mastery of the topics, no orderly association of the principles involved, and no formation of definite habits of response. There should be ample drills provided in pure numbers for the first four grades at least, with emphasis upon the processes, and then a gradual development into the other topics in such a manner as to show the genetic growth and derivation of the later from the earlier topics.

\section{Suggested Norms For Text-Books}

In order to bring together the best possible talent and experience for the making of texts in Arithmetic, there is needed the joint counsel of the business world to decide the most necessary topics to be included, of the pedagogist to tell what are the practical reactions of children in the school-room, and of the psychologist to follow out the latest suggestions of scientific discovery in the laws of mental behavior and growth.

Two prime questions are met in the preparation of the text- 
book:-(I) What topics are to be included; and (2) how shall they be treated, - as dissociated from the child's experience for purely cultural purposes, or as topics which deal with situations within the range of the child's daily life? An examination of the Arithmetics used now discloses the persistence of some topics from the remote past, even despite the fact that the practical business world long ago discarded them or has modified them almost beyond recognition. Partnership with Time was inherited from the Hanseatic League, which made practical use of it, but it has remained in the books for generations after it has been of any service, as an example of the conservatism of tradition. One sees small reason for including in any text for general school use such topics or subtopics as the Vermont Rule in Partial Payments, or even Partial Payments itself, or Foreign Exchange, Troy Weight, Apothecaries' Weight, Surveyor's Measure, Brick Layers' Work, Plastering, Lumber Measure, etc., any more than to put in also Bakers' Rules, Tailoring, Livery, Tobacco Manufacturing, Stock Raising, Dress Making, and scores of other special lines in which arithmetical laws may be of great service. The Metric System has no place in the grades of our American schools. The entire school should not be compelled to study something that only a small percentage of the pupils will ever get to use in scientific work later. It may well be made a part of high-school mathematics when it is needed.

Without further negative discussion, the following topics are suggested as reasonable and adequate to the real needs of the public schools:

I. Numeration and Notation. Hindu and Roman both to be presented.

2. The Four Fundamental Operations, Subtraction by the Austrian and Division by the Italian method.

3. Tables of Denominate Numbers, to include U. S. Money, Long, Dry, Time, Liquid, Avoirdupois, Square, Cubic, and Circular Measures.

4. Five Secondary Topics,-all possessing the Ratio Idea.

(a) Common Fractions, - approached from the side of Division.

(b) Decimal Fractions, - presented as a special form of common fractions whose denominator is always some multiple of Io, the numerator alone being written and the denominator indicated by the position of the point.

(c) Percentage,-presented as a special form of Decimals, with 100 as its denominator. Many practical problems touching such business lines as the majority of people come into contact with.

(d) Ratio,-which is only a special form of writing a common fraction, placing a colon vertically between numerator and denominator instead of a horizontal line between them in the usual manner.

(e) Proportion,-simply an equality of ratios. 
5. Square and Cube Root.

6. Mensuration: A distinct and separate subject to be approached objectively, with real objects and figures.

(a) Rectilinear Surfaces: rectangles, and triangles.

(b) Solids: including prisms, pyramids, cylinders, cones and spheres.

Under these six divisions the essential topics in general have been presented. An appendix might easily be added to suit particular communities, but it seems poor economy for publishers and the public to have a burden of highly specialized problems in the general text-book. In the appendix rural communities could be provided with rural problems, and those confined to strictly factory communities with problems suitable to their practical needs. It is not to be overlooked that the first six grades especially are to be provided with many more examples for drill purposes than are ordinarily afforded now. The Germans have always outdistanced us in this feature of arithmetical work. Their plan of publishing Hefte which contain from twenty to one hundred and fifty pages of examples, and selling for three to twelve cents each, has much to commend itself to us. Hentschel's Neue Rechenfibel, for instance, contains 32 pages, 3,760 examples, and sold for $33 / 4$ cents per copy. The French have issued many problem manuals for use in their schools, selecting much material from the official examination lists. We can improve this feature of our arithmetical work either by adding special appendices when it is desirable to have the examples and problems for drill in the same text with the development of the general theoretical side, and by the issuance of separate booklets of drill exercises in other instances.

Examples and Problems.-All arts and sciences have a right to their own technical nomenclature. Their terms, of necessity, must be more specialized than these terms are when used in the ordinary way. For this reason there seems to be a need of making a distinction between the exercises which deal only with pure numbers and those which apply numbers in stated situations. The writer believes it would be a great help if all text-books in Arithmetic would refer to all exercises in pure numbers as "Examples," and to all exercises in applied numbers as "Problems." Both oral and written exercises could be given under each one of these classes.

Algebra and Geometry-It will not appear radical now to advocate the introduction of some elements of Algebra and Geometry into the public school Arithmetic text. In handling numbers in the grammar grades the equation is of much ser- 
vice. In mensuration especially it is necessary to appeal to Geometry, as little intelligent work can be done there without some knowledge of geometrical figures and facts. In German and French schools use of these subjects has been resorted to for many years to illuminate the processes in Arithmetic. It is not advisable to eliminate Arithmetic from the 7 th and 8th grades in order to introduce separate texts in Algebra and Geometry. A gradual introduction of these principles may begin in the 5 th and 6th grades, and proceed with some definite matter fused with the more specific arithmetical facts. There is also an evident need of continuing Arithmetic into, if indeed not entirely through, the high-school. All the tests so far made show a lamentable weakness in Arithmetic in the higher grades. Recently Stratton (II8,336) has emphasized the need of sympathy between Arithmetic, and Geometry and Algebra. Too many teachers of secondary schools belittle Arithmetic, forgetting that the higher work depends upon it While the pupil has outgrown many of the minor problems he must still keep in close touch with arithmetical calculations in his more generalized mathematics. In 52 schools reporting to the American Committee of the International Commission on the Teaching of Mathematics, I9 introduce Algebra in the 7 th and 8th grades as Algebra, and 3 have work in Geometry other than what is needed in mensuration. In the schools of Germany, Geometry is usually begun now in the 6th grade. Out of 23,35I departments reporting in England 1,383 chose Algebra as an elective. Geometry is taught in about onefourth as many departments. It seems advisable to begin these two subjects early as companion subjects along with Arithmetic and continue Arithmetic into the high-school work. For this purpose the text-books should present all the necessary material.

\section{Some Suggested Norms For Teaching}

The many comparative experimental studies that have been made clearly demonstrate the fact that good courses of study, good superintendence, and well-educated teachers with plenty of equipment do not insure fruitful results. The Macedonian cry comes today from a multitude of teachers. Dyer in his recent report to the Boston School Committee (38,II) says : "The immediate and most urgent need felt by teachers is fresh light upon the art of teaching." The writer has been in somewhat close touch with the rural schools in the Mississippi Valley for the past two decades and he knows this con- 
dition that Dyer says exists in Boston is quite general,this one continuous entreaty for assistance. We have had an affluence of theory and a poverty of serviceable help in actual practice. Arithmetical texts should not be laden with pedagogic instruction to teachers. They need to avail themselves of the privileges afforded in State and City Normal schools, in Educational Departments in State Universities, in Teachers' Associations and Institutes, in works on pedagogy, and in school journals in order to get the most help in methods of teaching. This does not lessen the value of good text-books, built upon clear, pedagogical lines. Teachers who can really teach Arithmetic,-and the other common school subjects,with life, with delight, throwing around each recitation the best affective atmosphere so that every activity of pupil and teacher will be properly motivated, are today in great demand. Is not the dread of failure in school work the worst kind of failure?

Drill on Fundamentals.-Children enter school with some notion of number already formed, as has been shown. The teacher's early work with them should be intelligently based upon what they already know, and should keep in close touch with the child's mode of arriving at his first number-concepts. No book is needed. Abaci, splints, counters, and cards with large dots upon them may be used. Together with the presentation of sense-stimuli to be counted both simultaneously and in succession, the child soon may be taught the numbersymbols. Many children know these before entering school and it is well for the teacher to lead gently the child's interests rather than to attempt to drive or force them. No child seems to be exclusively visual-minded, or solely auditoryminded, or totally motor-minded, but each child is all of them at once, and may learn one fact in one channel and another fact in another channel. So the primary teacher will avail herself of all the means at hand to give the concepts of number in the completest and happiest forms, partly by presentation, partly by counting, and many times through the child's own movements. As has been earlier pointed out, children delight to count, perhaps because they can do it. Like older people they, too, worship at the shrine of achievement! It is also wise to have them measure and compare objects for basic work, but it is learned foolishness and pedagogic folly to insist, either in texts in the lower grades or in teaching Arithmetic in the grades that every time one divides 27 by 9 that 27 is necessarily " measured by the 9 and is therefore concrete." When written work is introduced it is better to place the digits under each other instead of in equation form as is the 
practice so generally in the first grade, since the future arrangement will be with figures under each other. Thus,

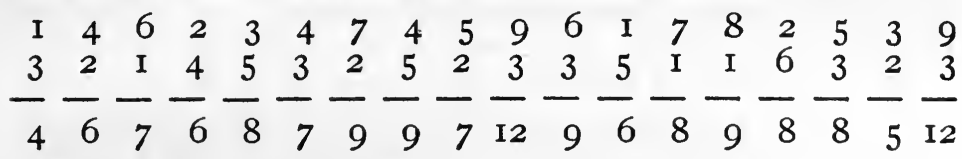

These are given merely as a suggestion on the form in which the very first written operations in addition should be expressed and no order of subject-matter is here attempted. The child should be given those forms and symbolic statements which he is to use first and new ones are to be brought in only as he needs them. Arithmetic should be adapted to the child and not vice-versa. It is best to use written subtraction in the Austrian form and written division in the long form by the Italian method. In all the four fundamental operations constant and consistent drill is required until the mechanical processes become habitual. If children are to be expert in handling numbers they should be thoroughly trained in the fundamentals before they come to the age of puberty. All the experimental studies warrant this conclusion. This appears to be the strategic time to emphasize work and drill with pure number, with examples, according to the definition set forth here.

Why Are Problems Harder Than Examples? - In examples the child has his processes clearly indicated for him in their statement. In problems, the case is very different. $\mathrm{He}$ has to "orient" himself arithmetically among words, words, words, which too frequently are scarcely within his comprehension. As was mentioned under the experimental studies, marked variations have been found in the difficulties of problems by a change of their wording. The pupil must know the meaning of all words used in the problem and also know the situation presented, and this demands that it deal with objects and situations familiar to the child. An intelligent and independent solution is possible only when the language employed is within his vocabulary and the situation within his experience.

Tables of Weights and Measures.-Early in the child's school experience the simpler measures, such as Long and Liquid Measures may be begun objectively, since most children at school entrance have a little knowledge of some of the units, such as foot, yard, gallon, pint, etc. All the tables should be approached as objectively as possible, so judgment may precede and strengthen memory. Longitude and Time is practical now only when the Standard Time belts are used. 
If it is approached from the geographical side, with proper drill upon the earth's rotation, it will not be necessary to commit rules about "when both points are east" or "when one is east of the prime meridian and one is west," since the mind grasps the situation objectively.

Fractions, Percentage, and Ratio.-At school entrance most children know what is meant by $1 / 2,1 / 3$, and possibly, $1 / 4$. Up through the first four grades the common fractions are gradually employed as they are needed, but in the $5^{\text {th }}$ grade they come in for fuller systematic treatment. Decimal fractions should follow a good understanding of common fractions, and should always be taught as a special form of common fractions, which themselves should be based upon Division. Any common fraction whose denominator is Io, or some multiple of IO, may be written as a decimal by simply writing its numerator and indicating its denominator by an agreed conventional use of the period for a decimal point. Percentage should be taught in very close relation to decimal fractions, since it is based upon the decimal whose denominator is always 100. If the genetic relation between common and decimal fractions, and between decimals and Percentage is clearly developed inductively these subjects will be vastly easier to teach and to learn than if they are taught as separate and unrelated subjects, as is so frequently done.

Solution of Problems. - The writer has found in teaching Arithmetic to several hundred Normal School students, the majority of whom had taught before entering his classes, three distinct hindrances to the intelligent solution of problems,Rules, Formulas, and Model Solutions. If text-books give rules or formulas or model solutions, students of advanced experience even are inclined to lean heavily upon them. This would suggest alertness upon the part of teachers in the grades to make sure that children are proceeding intelligently and are thinking the relations in the solutions. When a problem is attacked, the first step should be to read it carefully and pick out all the things that are granted, and to learn next what is to be found. One set of solutions here will serve to exemplify what is meant and also to correct some erroneous ideas that are found still in considering problems in Percentage. Keeping in mind all that has been said on the origin and nature of Percentage and the procedure with problems in general, let us take this problem:-

"If some goods are sold at a profit of $121 / 2 \%$, for $\$ 1,012.50$, what did they cost?"

Smith (105,74ff) in his latest book on Arithmetic uses this problem to show three erroneous methods of solution, and 
decides that the way out of the difficulty lies in employing an algebraic symbol for the cost. He entirely overlooks the intimate relation between Percentage and Decimal Fractions and treats it as a distinct part of Arithmetic, and this is a common weakness of arithmetical texts. His erroneous solutions, so far as they are arithmetical, should extend to four and include his own! Unnecessary appeals to Algebra cannot be sustained. When it is needed to use algebraic or geometrical principles to economize time and energy or in heightening the lucidity of the solution, no objection will be raised, but when this is made necessary because of a lack of proper connection between arithmetical topics, then it is to be condemned. If the Hundred-hundredths base-idea is grasped in Percentage, Smith's reasoning will be seen to deal with some "straw" sclutions. Coming back to the problem proposed for solution we shall first read it, and require that the facts granted, and the results asked for shall be clearly set forth before the solution proceeds and we have:
Granted (I) Selling price $=\$ 1,012.50$
(2) Gain per cent $=12.5$
Required (3) $\overline{\text { Cost }}=\overline{\text { what? }}$

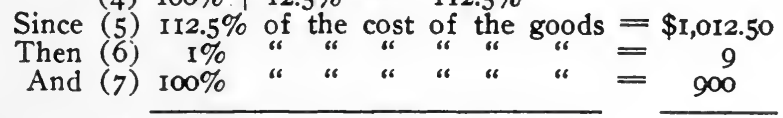

Hence (8) The cost of the goods $=\$ 900$

The words before the numbers of the equations are given merely to suggest the grouping of the facts of the problem, but are not necessary in the pupils' written work. Since the gain has been expressed in per cent in the problem, it is the most natural procedure to take $100 \%$ as the basis in the solution. When this fact is seen the rest of the work is self-evident. This is in perfect harmony with such solutions as the following:

I. Find three-eighths of 24 . Shall we let $5 / 5$ equal 24 , and then reason ourselves into adopting an algebraic symbol before we can solve this? Evidently, since the cue has been suggested in the fractional part, three-eighths, the obvious plan is this:

Since $8 / 8$ of $24=24$; then, $\mathrm{r} / 8$ of $24=3$; and $3 / 8$ of $24=9$.

2. Find $37.5 \%$ of 24 .

Since $100 \%$ of $24=24$; then, $1 \%$ of $24=.24$; and $37.5 \%$ of $24=9$.

3. 15 is $5 / 8$ of what number?

Since $5 / 8$ of a number $=15$; then, $\mathrm{r} / 8$ of it $=3$; and $8 / 8$ of it $=24$.

4. 15 is $62.5 \%$ of what number?

Since $62.5 \%$ of a number $=15$; then, $1 \%$ of it $=.24$; and $100 \%$ of it $=24$. 


\section{CONTRIBUTION TO THE PEDAGOGY OF ARITHMETIC}

This "unitary analysis" method grows directly out of the processes of common fractions, and is to be preferred to any method that is satisfied to get the "answer," and cares nothing about the relations of the separate steps in the work. The numbering of the steps has been found of some practical service in referring to the solutions, and is not an essential part of the work, - much as the pages of a book are numbered for convenience, but have no bearing upon the content of the book itself.

Inaccuracies.-Many text books and more teachers are careless in arithmetical statements. Each equation should be true within itself and should be as carefully expressed as accuracy demands. Arithmetic is nothing if it is not exact and accurate. One often finds the continued equation in books, somewhat like this: $6 \times 2=12 \div 4=3 \times 5=15$, in which the various members are not equal. The trouble arises in an attempt to put two or more separate steps into one statement. While the continued equation is sometimes true arithmetically, it is never correct grammatically. The equality sign is the principal verb, and the second member its object, which cannot properly serve both as the direct object of one verb and be the subject of the next principal verb! Many authors also continue to use such expressions as: " $100 \%=\$ 660$," and "Let $100 \%=\$ 660$," entirely disregarding the fact that per cent always means hundredths and that, therefore, I0o\% can equal nothing but $I$ or some expression reducible to unity. To say " $100 \%=\$ 660$ is to say that $I=\$ 660$; and to "Let $100 \%=\$ 660$ is to let $\mathrm{I}=\$ 660$, which is too apparently false to need further mention. The $\%$ sign should not be treated as an unknown quantity in Algebra. Yet, this fundamental error in handling this simple matter has led to endless confusion in the treatment of Percentage in the public schools.

Sources of Error.-The mistakes commonly found in the work of pupils in solving problems have these sources: $I$. Mistakes in reading the problem, (a) reversing figures, (b) not getting the meaning of the words, or (c) not understanding the situations involved, with wha: facts are granted and what is required;2. Inability to decide upon the processes to be used; and 3. Errors in computation. Each one of these mistakes calls for a specific kind of drill for its rectification. Careful work in the lower grades can do much to avoid them in the later work of the children.

Abstract and Concrete Numbers.-It is the belief of the writer that much useless and wasteful philosophising is attempted in the treatment of numbers in the grade work. It 
ought not to be regarded as sound pedagogy to try to force upon children the introspective and ratiocinative deductions of psychologists and philosophers about the nature of number. One may seek to discredit this position by calling it an appeal to the naive and laissez faire, but the suggestions have sufficient provocation. In his new book, Stamper (II3, 29) would almost confuse a philosopher with such statements as:

"Number is necessarily abstract." "The term abstract number strictly speaking expresses a redundancy, for number is essentially abstract. . . The abstract idea of number should be considered in multiplication and division problems. In multiplication, the multiplier is abstract, the multiplicand and product being concrete. . . . In division, the dividend is always concrete." (p. 30 .)

One cannot withhold the conviction that Stamper, although supporting the counting psychosis as the origin of number, since he says (p. 29): "Number has its origin in the counting process," yields to McClellan and Dewey when they state $(76,137)$ :

"The multiplicand must always represent a number of (primary) units of quantity (a measured quantity), and is commonly said to be concrete." "From the relation existing between multiplication and division, it is seen that in division the dividend, $\rightarrow$ or multiplicand as being a product of two factors, - always represents a measured quantity, $i$. e., it is concrete; the divisor may denote either a concrete quantity or a pure number and the quotient is, of course, numerical in the one case and interpreted as concrete in the other."

This philosophical reasoning has played havoc in practical school work, since teachers have striven to foist it upon the children even in the lower grades. Allen well says $(2,383)$ :

"If the child sees that each of seven boys has 5 cents, and wants to know how many all have, he will have little doubt as to whether he is repeating " 5 cents" "seven boys times," or "seven cents times" or just "seven times" and he will need no rule about abstract multipliers."

In other words, the natural movement of mind in handling these number combinations is more certain and more direct, if left unhampered by philosophical considerations and artificial rules. Wark (131, I62) claims:

"The most elementary counting, even that stage when the counts were not carried in the mind, but merely in notches on a stick or by DeMorgan's stones in a pot, requires some thought; and the most advanced counting implies memory of things. The terms, therefore, abstract and concrete number, have long since ceased to be used by thinking people."

Recently the writer visited an Arithmetic class in a State Normal and saw a group of practically adult students confused about this very question concerning abstract and concrete num- 


\section{CONTRIBUTION TO THE PEDAGOGY OF ARITHMETIC}

bers, according to their previous training in the conventionalities of the text-book. Their teacher diverted the work of the hour and she and the class spent almost the whole period in reestablishing the requirements "that the product must always be the same kind of unit as the multiplicand," and "addends must all be alike to be added." This is not an exceptional case. Throughout the whole range of teaching Arithmetic in the public schools pupils are obfuscated by the philosophical encumbrances which have been imposed upon the simplest processes of numerical work. The time is surely ripe, now we are readjusting our ideas of the subject of Arithmetic, to revise some of these wasteful and disheartening practices. Algebra historically grew out of Arithmetic, yet it has not been laden with this distinction. No pupil in Algebra lets $x$ equal the horses; he lets $x$ equal the number of horses, and proceeds to drop the idea of horses out of his consideration. $\mathrm{He}$ multiplies, divides, and extracts the root of the number, sometimes handling fractions in the process, and finally interprets the result according to the conditions of his problem. Of course, in the early number work there have been the senseobjects from which number has been perceived, but the mind retreats naturally from objectivity to the pure conception of number, and then to the number symbol. The following is taken from the appendix to Horn's thesis (57), where a 7 th grade girl gets the population of the United States in 1820 :

\begin{tabular}{l}
$7,862,166$ whites \\
233,634 free negroes \\
$1,538,022$ slaves \\
\hline $9,633,822$
\end{tabular}

In this problem three different kinds of addends are combined, if we accept the usual distinctions. Some may say that this is a mistake,-that the pupil transformed the "whites," "free negroes" and "slaves" into a common unit, such as "people" or "population" and then added these common units. But this "explanation" is entirely gratuitous, as one will find if he questions the pupil about the process. It will be found that the child simply added the figures as numbers only and then interpreted the result, according to the statement of the problem, without so much mental gymnastics. The writer has questioned hundreds of students in Normal School work on this point, and he believes that the ordinary mind-movement is correctly set forth here, no matter how well one may maintain as an academic proposition that this is not logical. Many classes in the Eastern Kentucky State Normal have been given this problem to solve, and they invariably get the same result: 
"In a garden on the Summit are as many cabbage-heads as the total number of ladies and gentlemen in this class. How many cabbage-heads in the garden?

And the black-board solution looks like this each time:

$$
\begin{aligned}
& 29 \text { ladies } \\
& 15 \text { gentlemen } \\
& 44 \text { cabbage-heads }
\end{aligned}
$$

So, also one may say: I have 6 times as many sheep as you have cows. If you have 5 cows, how many sheep have I? Here we would multiply the number of cows, which is 5 , by 6 and call the result 30 , which must be linked with the idea of sheep because the conditions imposed by the problem demand it. The mind naturally in this work separates the pure number from its situation, as in Algebra, handles it according to the laws governing arithmetical combinations, and labels the result as the statement of the problem demands. This is expressed in the following, which is tacitly accepted in Algebra, and should be accepted equally in Arithmetic:

In all computations and operations in Arithmetic, all numbers are essentially abstract and should be so treated. They are concrete only in the thought process that attends the operation and interprets the result.

Mental, or Oral, Arithmetic.-Much oral drill should be given in all the first six grades. Processes should become almost automatic by the close of these grades. The German schools excel in Kopfrechnen, and our American schools can well afford to return to the practice of a generation ago in this matter.

The writer does not think that he has spoken the last word for improvements needed in teaching and in studying Arithmetric, but he does believe that he has pointed to some reliefs from the present discouragements in the results. There is no gainsaying his position that, in the ultimate analysis, the failure to respond quickly and correctly to problems in Arithmetric lies in the mental inability of the child. And beyond this fact we must remember that the child must do his own thinking in the subject. No superintendent, no teacher, no course of study, no text-book can do more than provide him with the proper stimuli and direction for his own development. Growth must come from within. Tests and experimental studies, such as have been brought together in this dissertation, will assist in discovering to us the child's reactions to numbers and to problems involving numbers, and in this way serve to adapt the means of the school to the ends of 
individual education. A sensible synthesis of all that has been found good in these studies, and that may yet be disclosed in similar investigations, will hasten the Renaissance in Arithmetic.

\section{General Summary}

I. Arithmetic is one of the chief subjects in the first eight grades of the schools throughout the civilized world. It receives about one-sixth of the total school time.

2. Children show some interest in numbers about the close of their fourth year, and at school entrance at six they have quite well formed ideas of numbers up to 8 or 10. Many are able to count 100 or more.

3. One school of educators holds that the number concept arises from simultaneously perceived groups of objects; another school holds that number is gained from successively perceived stimuli. One would teach by presenting many objects in a group; the other would teach by counting.

4. No definite correlation has been found to exist between the number systems employed by primitive peoples and their civil development. Number systems are known to arise readily when these are needed.

5. Both primitive peoples and children have a natural tendency to symbolisms and this fact makes the growth of the number symbols easy for them.

6. One group of educators advocates deferring number work until one or two grades have been completed by the child in school. Another group favors the usual practice of starting children in numbers as soon as they enter school at six years of age. The child's pre-school interest in numbers would support the latter group, while the successful number work reported by the English Infant Schools and by Montessori is also favorable to this view.

7. The influence of puberty upon arithmetical interests and abilities has been found to be very marked, and it should be clearly understood by teachers who handle children of the postpubertal period.

8. Drill work has been found exceedingly valuable for developing skill in handling numbers rapidly and accurately. Short periods are better than the same total time used in long periods of drill. The permanent effect of drill-work has been found to be much greater than was supposed.

9. Children are inclined to make certain habitual "typeerrors." These should be carefully listed by teachers and made the subject of vigorous drill. Much time is squandered in going over matter which the children already know in most 
schools, and energy is not concentrated upon the particular difficulties that should be attacked.

Io. If problems in Arithmetic are made to deal with situations within the experience of pupils, the subject will be robbed of much of its present tedium.

II. The adoption of a "fixed standard" for achievement in Arithmetic, rather than a progressive one, threatens to work great harm in the schools. The criterion by which to judge the results of teaching should be a growing one, or stagnation will be encouraged.

12. The wording of problems, which are to be distinguished from examples, should receive careful attention in the textbooks.

I3. Great individual differences exist among children concerning Arithmetic. These variations range from dread aversion to the subject all the way to special favoritism for it. Early impressions received from parents, tutors, associates, and school experiences all seem to have some influence in determining the Einstellung of the pupils toward Arithmetic.

14. Girls have been found to excel boys generally in practical skill in computations, but boys are better than girls in reasoning upon number situations.

15. Children in the first five grades do not have the range of attention or the power of concentration that the children in the upper grades possess. The dawn of adolescence marks the dividing line between the two types.

16. Habits of rapid and accurate handling of numbers must be thoroughly established in the first five grades. Drill to this end should be begun as early as possible after school entrance, and carried forward with special care in the 3 rd, $4^{\text {th }}$, and $5^{\text {th }}$ grades. Habits of combining numbers quickly should be firmly fixed and hierarchies of habits should respond automatically to given processes, while whole federations of hierarchies should gather spontaneously to solve questions involving several processes. Much drill should be afforded with pure numbers, and a minimum of problems involving a study of situations resorted to.

I7. Problems may be begun in the 6th grade with profit, and the work will be attractive and inviting if the pupils can perform the operations with ease.

I8. Philosophical distinctions between abstract and concrete numbers are not to be urged upon the children in the elementary schools. However true these distinctions are in logic, to teach them in the grades serves no useful or needful end, and adds to the burden of dealing with practical applications of number.

I9. Oral, or mental, Arithmetic deserves a wide place in the 
early grades, and should not be omitted even from the upper grades. Kopfrechnen has a value that pencil and crayon can never supplant.

20. Instead of teaching Arithmetic in the eight grades of the elementary school, Algebra in the first two grades of the high school and Geometry in the last two high school grades, it would be better from several considerations to teach Elementary Mathematics through the entire twelve grades, introducing Algebra and Geometry as early as they can be of real service, and continuing Arithmetic into the high school.

21. Text-books in Arithmetic should have the combined experience and knowledge of the business man, the psychologist, and the pedagogist. If the authorship of texts combines these three interests, a much more practical and teachable book will result.

22. The derivative relation of Common Fractions, Ratio and Proportion to Division; of Decimals to Common Fractions; and of Percentage to Decimals should be clearly set forth in the text-books, beyond which so few teachers are disposed to go in their teaching. This change in the books would do more than any one other thing to clarify the topics, which stand now as apparently separate and unrelated topics to be treated independently.

\section{Bibliography.}

I. Aley, R. J. and McNiexl, I. C. Mathematics in the Grades. N. E. A. Report, 1908, pp. 569-576.

2. AILEN, FISKE. Is Arithmetic a Science of Numbers or of Symbols? Kansas School Magazine, vol. I, no. 9, Nov., I912, pD. $378-384$.

3. Alling-A BeR, Mary R. An Experiment in Education. New York, Harpers, I897, 245 p.

4. ANDrews, W. S. Magic Squares. Monist, vol. 15, pp. 42946I, 554-586. Magic Cubes. Monist, vol. 16, pp. 328ff.

5. ArNetr, L. D. Counting and Adding. Amer. Jour. Psychol., vol. I6, no. 3, July, I905, pp. 327-336.

6. Badanes, Saul. The Falsity of the Grube Method of Teaching Primary Arithmetic. New York University thesis, 1895, $47 \mathrm{p}$.

7. BaILeY, M. A. and Соoк, John W. The Teaching of Arithmetic in Elementary Grades. N. E. A. Report, 1895, pp. 380-387.

8. BALL, W. W. R. A Short Account of the History of Mathematics. London, Macmillan, I888, 464 p.

9. Ballard, P. B. The Teaching of Mathematics in London Public Elementary Schools. Ed. Dept., Great Britain Special Rep., vol. 26.

10. BoAs, Franz. Language and Thought. Introduction to the Handbook of American Indian Languages. Washington, Gov. Print. Office, I9II, $1069 \mathrm{p}$. 
II. Branford, Benchara. A Study of Mathematical Education, including the Teaching of Arithmetic. Oxford, Clarendon Press, 1908, 392 p.

12. Brooks, S. D. Annual Report of the Superintendent, July, 1910, School Document No. Io, I910, Boston Public Schools.

I3. Brown, J. C. An Investigation on the Value of Drill Work in the Fundamental Operations in Arithmetic. Jour. of Ed. Psychol., vol. 2, Feb., I9II, 8I-88; vol. 3, Nov., I9I2, 485-492; Dec., 1912, 56I-570.

14. Brown, William. The Psychology of Mathematics. Child Study, vol. 6, March and April, 1913, 24-26; 42-47.

15. Browne, C. E. The Psychology of the Simple Arithmetical Processes. Am. Jour. Psychol., vol. 17, 1906, I-37.

16. Bruce, H. A. B. Bending the Twig. American Magazine, vol. 69, 1910, 690-695.

I6a. Bryan, W. L. and Harter, N. The Telegraphic Language. Psych. Rev., vol. 6, no. 4, July, I899, 345-375.

17. Burnham, W. H. Arithmetic and School Hygiene. Ped. Sem., vol. I8, I9I I, 54-73.

18. Cajori, Florian. A History of Mathematics. New York, Macmillan, I894, $422 \mathrm{p}$.

19. Calfee, J. E. Rural Arithmetic. Boston, Ginn and Co., I9I3, II9 $\mathrm{p}$.

20. CA M PBell, C. V. Courses in Arithmetic. N. Y. Teachers Monographs, I9I2, 28-34.

21. CARMichaes, R. D. A Lesson from the History of Numbers. School Sci. and Math., vol. I3, no. 5, May, I913, 392-399.

22. Chartres, W. W. Teaching the Common Branches. Boston, Mifflin, 1913, $355 \mathrm{p}$.

23. Cole, L. W. Adding Upward and Downward. Jour. Ed. Psychol., vol. 3, Feb., 1912, 83-94.

23a. Colburn, WARREN. Teaching of Arithmetic. Elementary School Teacher, vol. I2, June, I9I2, pp. 463-480.

24. Conant, L. L. Historical Development of Arithmetical Notation. Ped. Sem., vol. 2, I49-152.

25. - The Number Concept. New York, Macmillan, I8g6, $218 \mathrm{p}$.

26. Cosby, Byron. Arithmetical Teaching,-An Experiment in the Mound City, Mo., Public Schools. School Sci. and Math., vol. II, I9I I, 629-634.

27. Courtis, S. A. Standard Tests in Arithmetic. Jour. Ed. Psychol., vol. 2, I9II, 272-274.

28. - Standard Scores in Arithmetic. Elementary School Teacher, vol. 12, Nov., 1912, 127-137.

29. - Measurement of Growth and Efficiency in Arithmetic. Elementary School Teacher, vol. 10, Oct., 1909, 58-74; Dec., 1909, I77-199; vol. II, Dec., I910, I7I-185; March, I9II, 360-370; June, 1911, 528-539.

30. - Report on the Courtis Tests in the City of New York, IgII-I9I2. Interim Report, Committee on School Inquiry, Board of Estimate and Apportionment. I9I3, I58 p.

3I. - Bulletin No. 2, Courtis Standard Tests. Detroit, Aug., 1913, 44 p.

32. Dawson, N. H. R. Simplification of Arithmetic. U. S. Com. Ed. Rep., I886-7, 238-239.

32a. DeARBorn, G. V. N. Moto-Sensory Development. Baltimore, Warwick \& York, "1910, 215 p. 
33a. Decroly, Dr. M. le, and Degand, Mlle. Julia. L'evolution des notions de quantites continues et discontinues chez L'enfant. Arch. d. Psych., vol. I2, I9I2, pp. 8I-I2I.

33. DeMorgan, Augustus. Arithmetical Books from the Invention of Printing down to the Present Time. London, Taylor and Walton, 1847, $124 \mathrm{p}$.

34. - On the Study and Difficulties of Mathematics. Chicago, Open Court Pub. Co., I 898,288 p.

35. Deuchler, G. Psychologische Vorfragen des ersten Rechenunterrichts. Zeits. f. päd. Psych., 1912, vol. 13, 36-52.

36. Dolbear, Katherine E. Precocious Children. Ped. Sem., vol. I9, no. 4, Dec., I9I2, 46I-49I.

37. Dooley, W. H. Arithmetic in a Massachusetts Industrial School. School Sci. and Math., vol. II, I9II, 246-249.

38. DYER, F. B. Annual Report of The Superintendent. Boston, Dec. I5, I9I3, 244 p.

39. ElIOT, CHAS. W. Shortening and Enriching the Grammar School Course. N. E. A. Rep., I892, 617-620.

40. ERLER, OTTO. Zahlengedächtnis und Rechenfertigkeit. Zeit. f. päd. Psych., vol. 12, I9I I,294-295.

40a. FreEman, F. N. Uber den Aufmerksamkeitsumfang u. die Zahlauffasung. Leipzig, Hahn, I9Io, pp. 88-168.

4I. Galton, Francis. Inquiries into Human Faculty and Development. London, Macmillan, I883, $387 \mathrm{p}$.

42. Gartland, P. G. Two Experiments on Grammar School Graduates. School Sci. and Math., vol. II, I9I I, I55-I59.

43. GILBERT, C. B. What Children Study and Why. Boston, Silver, Burdett and Co., 1913, 33I p.

44. Gildemeister, Thelda. Mathematics in the Elementary Schools of the United States. U. S. Bureau Ed. Bul., I9I I, whole no. 460, 75-120.

45. Giles, J. T. The Scientific Study of Arithmetic Work in School. N. E. A. Rep., 1912, 488-492.

46. Gow, JAMES. A Short History of Greek Mathematics. Cambridge, University Press, 1884, 323 p.

47. GREENwOOD, J. M. Verbatim Report of Recitations in Arithmetic and Language in the Schools of Kansas City, Mo., U. S. Com. Ed. Rep., 1893-4, vol. I, 557-594.

48. - Report of the Committee of Fifteen-Dissent on Arithmetic. U. S. Com. Ed. Rep., I893-4, vol. I, 532-4; or N. E. A. Rep., I895, 333.

49. - and Martin, A. Notes on the History of American Textbooks on Arithmetic. U. S. Com. Ed. Rep., 1897-8, vol. I, 789-868; 1898-9, vol. I, 781-837.

50. Griggs, A. O. Pedagogy of Mathematics. Ped. Sem., vol. I9, 1912, 350-375.

51. Hall, F. H. and Gilbert, N. D. Imagination in Arithmetic. N. E. A. Rep., I897, 621ff.

52. Hall, G. Stanlex. Educational Problems, New York, Appleton, I9II, 2 vols., I424 p. See "The Pedagogy of Elementary Mathematics," vol. 2, 34I-396.

52a. - Adolescence. New York, Appletons, 1904, vol. I, $589 \mathrm{p}$.

53. HaRris, W. T. Report of the Committee of Fifteen. U. S. Com. Ed. Rep., I893-4, vol. I, 497-502; or N. E. A. Rep., I895, 296-30I. 
54. Harrison, A. S. The Demonstration School Record No. 2. The Pursuits of the Fielden School, Manchester, Eng. University Press, 1913, 275 p.

55. Hart, W. W. Community Arithmetic for Seventh and Eighth Grades. Elementary School Teacher, vol. II, 285-295.

56. - Mathematics in the Elementary Schools of the United States. U. S. Bureau Ed. Bul. No. I3, I9II, whole no. $460,16-65$.

57. Horn, ERnest. Experiment in Seventh Grade Arithmetic. Univ. of Mo., master's thesis, 1908. Typewritten, 69 p. with appendix. (Borrowed from Univ. of Mo. Library.)

58. HoRnBRook, A. R. An Open Letter to Students Teaching Arithmetic in the Training Department. San Jose, Cal., I913, 20 p.

59. Jackson, L. L. The Educational Significance of Sixteenth Century Arithmetic. New York, Teachers College, 1906 232 p.

60. JÄNICKE, E. Geschichte der Methodik des Rechenunterrichts, vol. 3, Kehr's Geschichte, Gotha, Thiermann, r888.

6r. Jefrrey, G. R. Some Observations on the Use of the "Reckoning Tests." Jour. Exp. Ped., vol. I, 191 I-12, 392-396.

62. Josephus, Flavius. Antiquities of the Jews. Philadelphia, Porter, 1829, $978 \mathrm{p}$.

63. JUDD, C. H. Studies in Principles of Education. Initiative, or the Discovery of Problems. Elementary School Teacher, vol. 13, 1912-3, 146ff.

64. KikUchI, B. D. Japanese Education. London, Murray, I909, $397 \mathrm{p}$.

65. KIRBY, T. J. Practice in the Case of School Children. New York, Teachers College, 19r3, 98 p.

66. Knilling, R. Die Naturgemässe Methode des Rechenunterrichts in der Deutschen Volksschule. Munich, Oldenbourg, I897-9, 2 vols., 372 p. and 266 p.

67. LAY, W. A. Führer durch den ersten Rechenunterrichts naturegemässes Lehrverfahren gegründet auf psychologische Versuche und angeschlossen an die Entwicklungsgeschichte des Rechenunterrichts. Karlesruhe, Nemnich, I898, $155 \mathrm{p}$.

68. - and ENDERLIN, M. Führer durch das erste Schuljahre. Leipzig, Quelle, I9I I, 434 p.

69. - Alte und Neue Experimente zum ersten Rechenunterricht. Zeits. f. exp. Päd., Bd. I, I29-166.

70. Lessing, T. Pädagogik und Psychologie der Mathematik. Zeits. f. exp. Päd., Bd. 9, 225-237.

71. Lewis, E. O. Popular and Unpopular School Subjects. Jour. Exp. Ped., June, I9r3, vol. 2, no. 2, 89-98.

72. LieTzManN, W. Stoff und Methode des Rechenunterrichts in Deutschland. Leipzig, Teubner, I912, I07 p.

73. LoBSIEN, M. Korrelation zwischen Zahlengedächtris und Rechenleistung. Zeits. f. exp. Päd., Bd. 12, 54-60.

74. Lucas, Edouard. Theorie des Nombres. Paris, Gauthier, I891, $520 \mathrm{p}$.

74a. MÁDAY, StEFAN v. Die Fähigkeit des Rechnens beim Menschen und beim Tiere. Zeits. f. angewandte Psychol. u. psych. Sammelforschung, Bd. 8, Heft, 3 u. 4, pp. 204-227.

75. MAJOR, D. R. First Steps in Mental Growth. New York, Macmillan, $1896,360 \mathrm{p}$. 
76. Mclellan, J. A. and Dewey, John. The Psychology of Number. New York, Appleton, 1895, 309 p.

77. Mecker, H. H. A Study in Seventh Grade Subject Matter. Thesis, 19I3, Univ. of Mo., typewritten, 84 p. (Borrowed from U. of Mo. Library.)

78. Messenger, J. F. The Perception of Number. New York, Macmillan, 1903, $44 \mathrm{p}$.

79. MeumanN, ERNST. Vorlesungen zur Einführung in die Experimentelle Pädagogik und ihre Psychologischen Grundlagen. Leipzig, Englemann, 1907, 2 vols.

80. - Ueber die Anlage zum Rechnen. Zeits. f. exp. Päd., Jahr. I4, Feb., I9I3, II7-II8.

81. Mill, J. S. Demonstration and Necessary Truths. A System of Logic, bk. 2, ch. 6, New York, Longmans, 1900.

82. Miluis, J. F. The Solution of Problems. Kansas School Mag., vol. 2, no. 9, Nov., 1913, 305-310.

83. Montessori, M. The Montessori Method. New York, Stokes, 1912, 377 p. See chap. 9, "Teaching of Numeration; Introduction to Arithmetic."

84. Münsterburg, Hugo. Psychology and the Teacher. New York, Appletons, 1909, 330 p.

85. Myers, C. S. Introduction to Experimental Psychology. Cambridge, Univ. Pr., I9I I, I56 p.

86. Nanu, Helene A. Zur Psychologie der Zahlauffasung. Würzburg, Becker, 1904, 56 p.

87. Newcomb, Simon and Aley, R. J. The Teaching of Arithmetic. N. E. A. Rep., 1906, 86-102.

88. Paine, Cassie L. A Strong Motivation for Arithmetic Work. Elementary School Teacher, vol. I3, April, r913, 379-386.

89. PALMER, G. W. The Teaching of Arithmetic in Secondary Schools. Great Britain Special Ed. Rep., vol. 26, 224-256.

90. Payne, B. R. Public Elementary School Curricula. New York, Silver, Burdett and Co., 1905, $200 \mathrm{p}$.

91. Perry, A. C. Problems of the Elementary School. New York, Appletons, I9Io, $224 \mathrm{p}$.

92. Phelps, C. L. A Study of Errors in Tests in Adding Ability. Elementary School Teacher, vol. 16, no. I, Sept., 1913, 29-39.

93. Philuips, F. M. Value of Daily Drill in Arithmetic. Jour. Ed. Psychol., vol. 4, no. 3, March, 1913, I59-163.

94. Philuips, D. E. The Genesis of Number Forms. Amer. Jour. Psychol., vol. 8, no. 4, July, I897, 506-527.

95. - Number and its Application. Ped. Sem., vol. 5, no. 2, Oct., I897, 221-281.

96. Preyer, W. The Mind of the Child. New York, Appletons, I889, 3I7 p.

97. RANSCHBURG, P. Zur physiologischen und pathologischen Psychologie der elementaren Rechenarten. Zeits. f. exp. Päd., Bd. 7, 135-162, 1908; Bd. 9, 1909, 25I-263.

98. RICE, J. M. Scientific Management in Education. New York, Publishers Printing Co., I913, 282 p.

99. Rusk, R. R. Introduction to Experimental Education. London, Longmans, 1912, $303 \mathrm{p}$.

I00. Santerre, S. Psychologie du Nombre et des Operations elementaire de L'Arithmetique. Paris, Doin, I907. 178 p.

IOI. SCRIPTURE, E. W. Arithmetical Prodigies. Amer. Jour. Psychol., vol. 4, no. I, also reprint, Worcester, Mass., I89I, $56 \mathrm{p}$. 
rora. Schanoff, Botju. Die Vorgänge des Rechnens. Pädagogische Monographien, Bd. XI., Leipzig, I9II, I20 p.

102. ShAw, O. A. Arithmetic Philosophically Taught, or a Description of the Visible Numerator. Boston, Marvin, 1832, $95 \mathrm{p}$.

103. Smith, A. C. The Teaching of Arithmetic. School Sci. and Math., June, 1912, vol. 12, 457-460.

I04. Smirh, D. E. The Teaching of Elementary Mathematics. New York, Macmillan, I901, 312. p:

105. The Teaching of Arithmetic. Boston, Ginn and Co., 1913, $196 \mathrm{p}$.

106. Early Drill in Arithmetic. Kansas School Mag., vol. I, no. 3, March, 1912, 95-IOI.

107. - Article on "Arithmetic" in Monroe's Cyclopedia of - Education. New York, Macmillan, I9II, 5 vols.; vol. I, 203-207.

108. The International Commission on the Teaching of Mathematics. Ed. Rev., vol. 45, January, 1913, I-7.

109. - Sex in Mathematics. Ed. Rev., vol. 9, 1895, 84-88.

IIO. Sonnenschein, A. The Study of Arithmetic in Elementary Schools. Great Britain Spec. Rep. on Ed. Subj., vol. 8, I902, 57 I- 585 .

III. Smitr, W. H. All the Children of All the People. New York, Macmillan, I912, $335 \mathrm{p}$.

112. SPENCER, H. J. The Teaching of Mathematics in the English Public Elementary Schools. Great Brit. Spec. Ed. Rep., vol. 26 , 1912, 3I-60.

II3. Stamper, A. W. A Text-book on the Teaching of Arithmetic. New York, American Book Company, 1913, $284 \mathrm{p}$.

I14. Starch, Danies. Transfer of Training in Arithmetical Operations. Jour. Ed. Psychol., vol. 2, 306-3IO.

I15. Stephens, IrENE. The Teaching of Mathematics to Young Children. Great Brit. Sp. Ed. Rep., vol. 26, 1912, 6I-79.

II6. Strtr, E. W. School and Business Arithmetic. N. E. A. Rep., 1900, 566-572.

I17. Stone, C. W. Arithmetical Abilities and Some Factors Determining Them. New York, Teachers College, 1908, I02 p.

II8. - Problems in the Scientific Study of Teaching Arithmetic. Jour. Ed. Psychol., January, I9I3, vol. 4, no. I, I-I6.

IIg. Stone, J. C. The Modernization of Arithmetic. 'N. E. Jour. Ed., vol. 78, Dec. 4, 1913, 573-578.

120. Stratton, W. F. The New Thought in Arithmetic. Kansas School Mag., Dec., 1913, vol. 2, 336-7.

I21. SuLly, JAmes. Studies of Childhood. New York, Appletons, $1896,527 \mathrm{p}$.

122. Suzzalo, Henry. The Teaching of Primary Arithmetic. Boston, Mifflin, I9II, I24 p.

123. Tear, J. H. and $\operatorname{Cox}, H$. C. The New Arithmetic. N. E. A. Rep., 1897, 630-6.

124. Thом., F. J. Lay's "Führer durch den Rechenunterrichts" und das Rechnen auf Grund der gegliederten Reihe. Zeits. f. exp. Päd., Bd. II, 1910, 15-123.

125. Thorndike, E. L. Effect of Practice in the Case of a Purely Intellectual Function. Amer. Jour. Psychol., vol. I9, July, I908, 374-384.

126. 1908, 374-384. Practice in the Case of Addition. Amer. Jour. Psychol., vol. 2I, July, 19I0, 483-6.

127. The Measurement of Educational Products. School Rev., vol. 20, no. 5, May, 1912, 289-309. 


\section{CONTRIBUTION TO THE PEDAGOGY OF ARITHMETIC}

128. —_ Educational Psychology, vol. 2. New York, Teachers College, 1913, 452 p. See chap. 7. "Amount, Rate and Limit of Improvement."

129. TROPFKE, J. Geschichte der Elementar-Mathematik in systematischen Darstellung. Erst. Bd.: Rechnen u. Algebra, Leipzig, Veit, 1902, $332 \mathrm{p}$.

130. VoIgt, W. Ueber die Anlage zum Rechnen. Arch. f. Päd., 2. teil, vol. I, I912, I29 ff.

131. WARK, ANNA L. Early Work in Number. Chap. in Education by Life, edited by Henrietta Brown Smith, London, Philip, I912, 2II p.

132. WEBB, H. E. The Re-introduction of Arithmetic into the High School Course. School Sci. and Math., vol. 13, no. 6, June, I913, 517-524.

133. WeLLS, F. L. The Relation of Practice to Individual Differences. Amer. Jour. Psychol., vol. 23, no. I, January, I912, $75-88$.

134. Whitley, M. T. An Empirical Study of Certain Tests for Individual Differences. Arch. of Psychol., no. 19, August, I9I1, I46 p.

135. Wrlitams, T. A. Intellectual Precocity. Ped Sem., vol. 18, March, 19II, 85-103.

136. Winch, W. H. Mental Adaptation during the School Day as Measured by Arithmetical Reasoning. Jour. Ed. Psychol., Jan., 1913, vol. 4, no. I, 17-28; Feb., 1913, vol. 4, no. 2, 71-84.

137. - - Accuracy in School Children: Does Improvement in Numerical Accuracy "Transfer?" Jour. Ed. Psychol., vol. I, 1910, 557-589; vol. 2 , I911, 262-271 and 334-336.

138. Yocum, A. D. An Inquiry into the Teaching of Addition and Subtraction. Philadelphia, Avil Print. Co., r90I, 92 p.

139. - A First Step in Inductive Research into the Most Effective Methods of Teaching Mathematics. School Sci. and Math., vol. I3, no. 3, March, I913, 197-210.

140. Young, J. W. A. The Teaching of Mathematics. New York, Longmans, 1907, 35I p.

141. The Fifth International Congress of Mathematicians. School Sci. and Math., vol. 12, 1912, 702-715. 






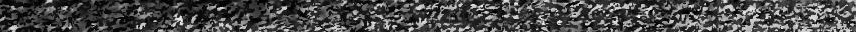

1.

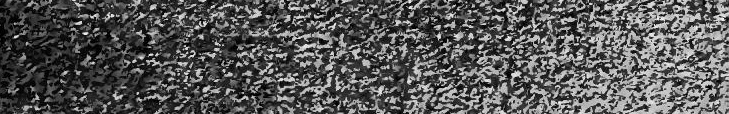

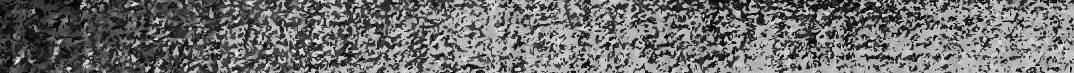
3
10

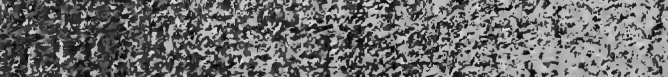

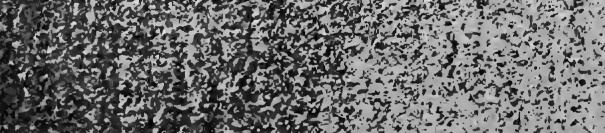

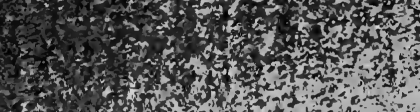

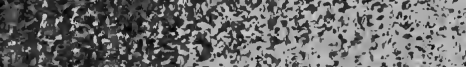

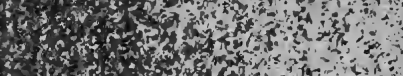

i. 10.7 .

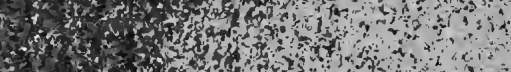

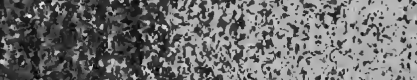

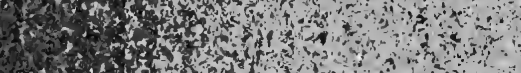

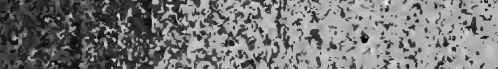

(1)

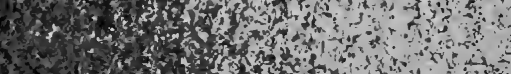

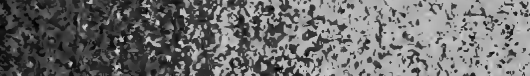

tow

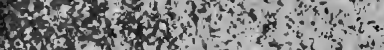

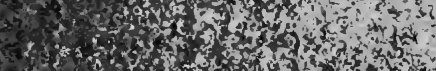

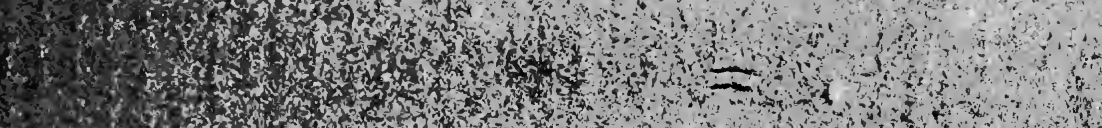

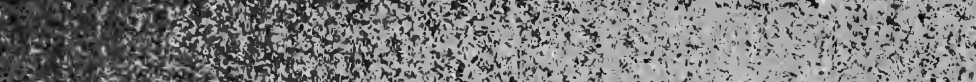

7 1

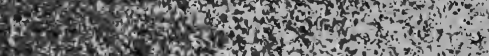

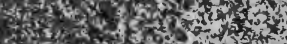

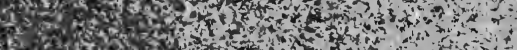

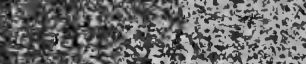

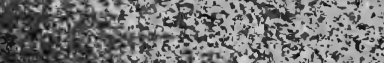

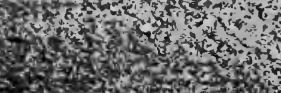

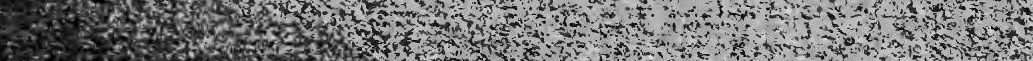

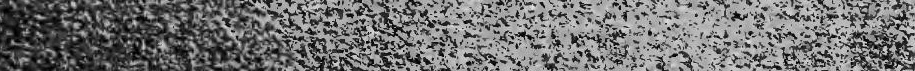

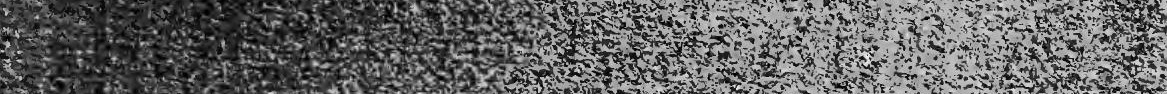

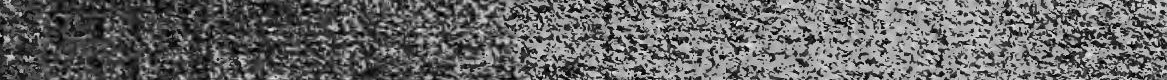

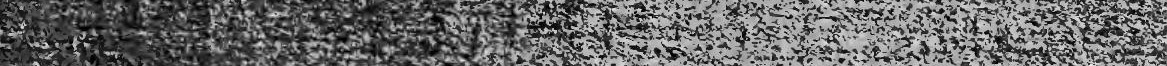

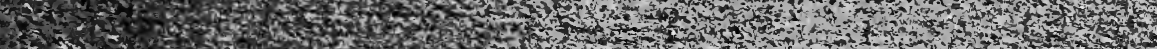




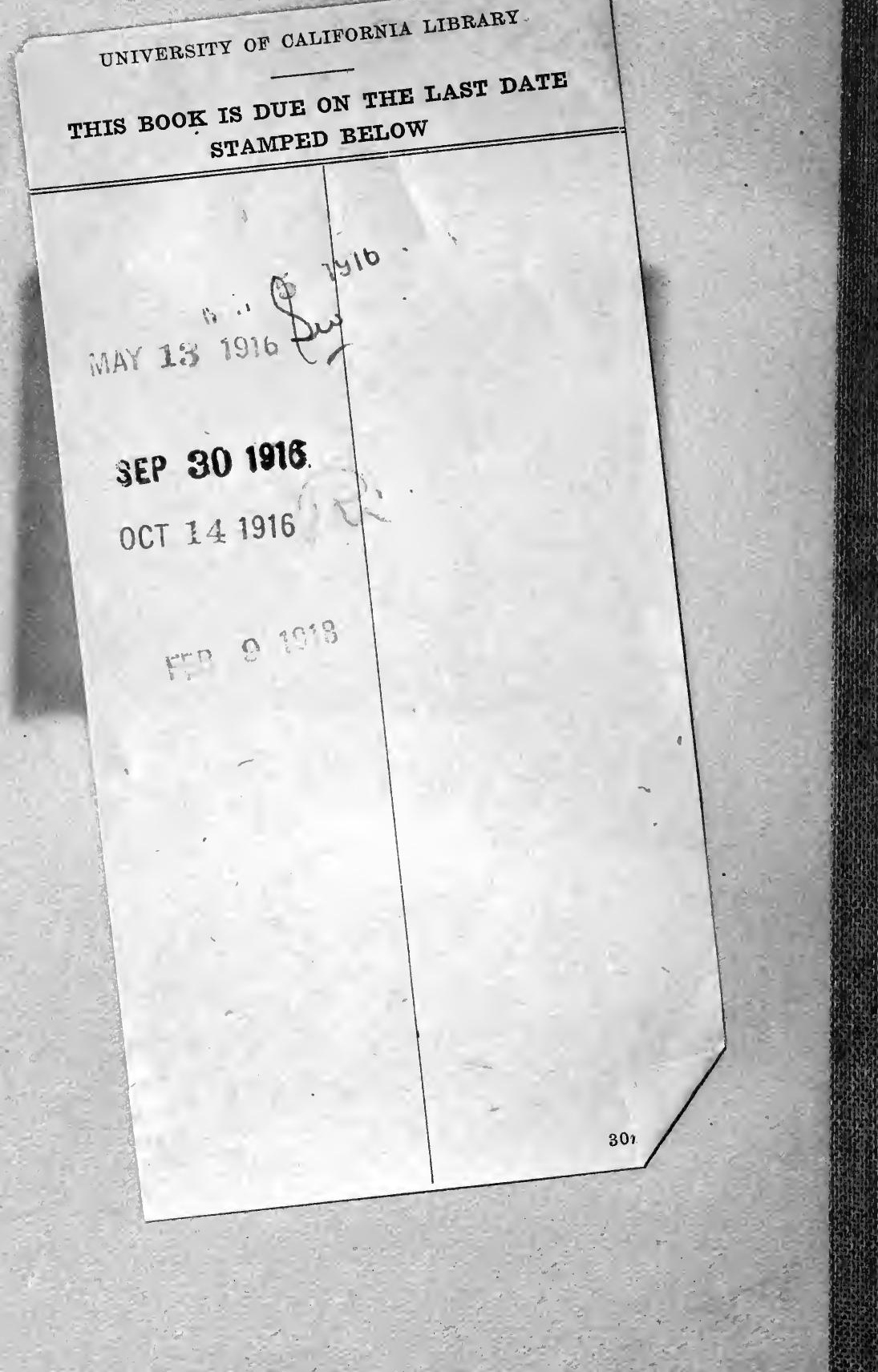




$$
\begin{aligned}
& 293417 \\
& \text { met } \\
& \angle B / 589 \\
& \$ 12
\end{aligned}
$$

UNIVERSITY OF CALIFORNIA LIBRARY 


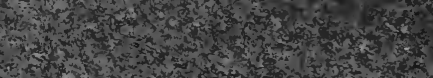

and

4

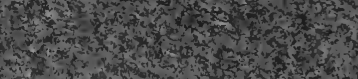

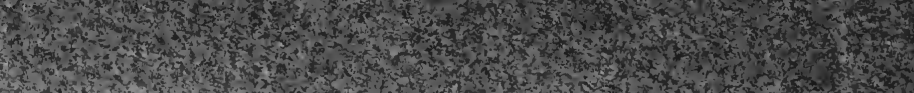

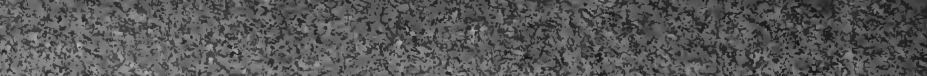

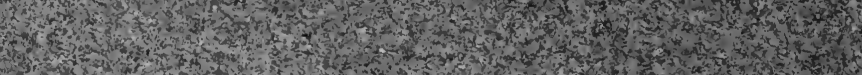

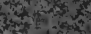

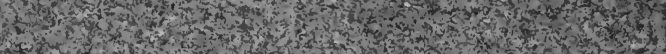

(n)

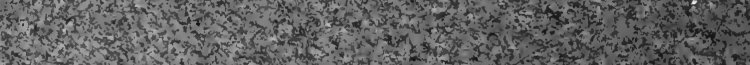

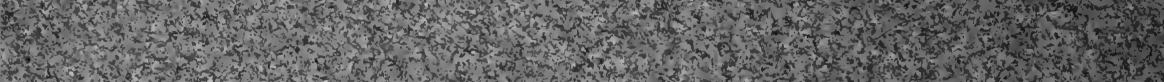

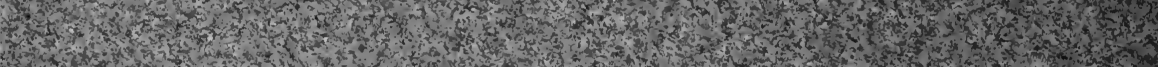

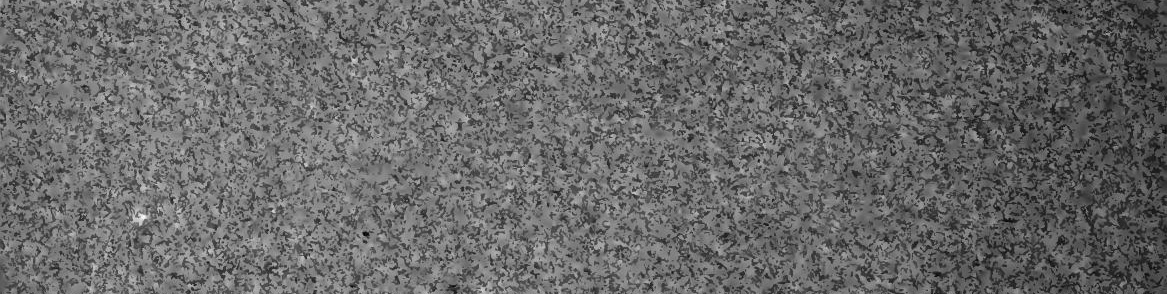

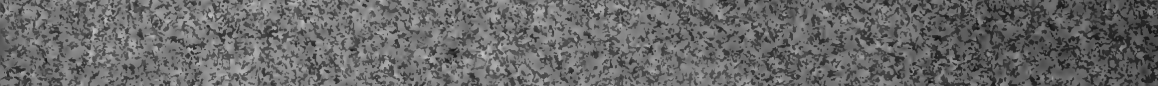

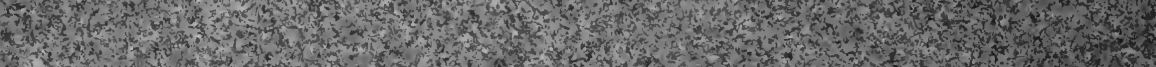

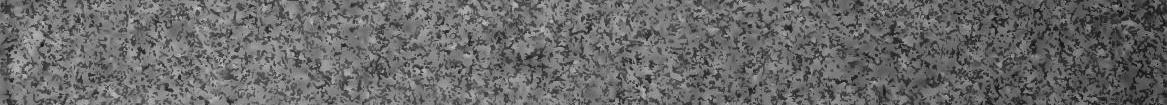
H. 3
3

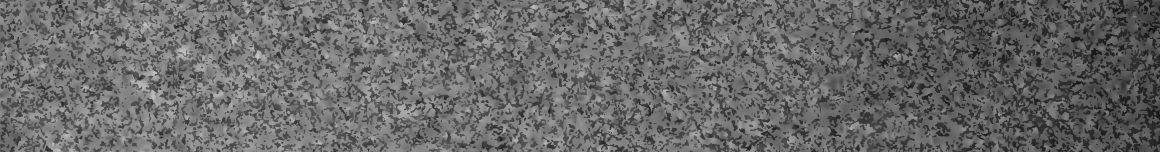

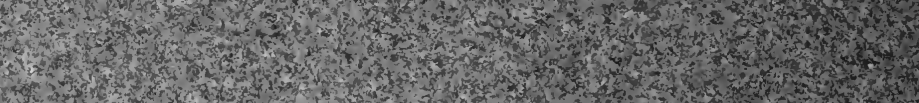
14.

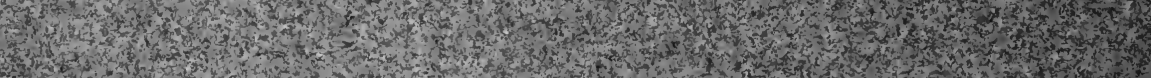

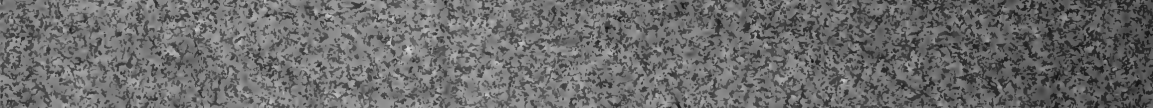

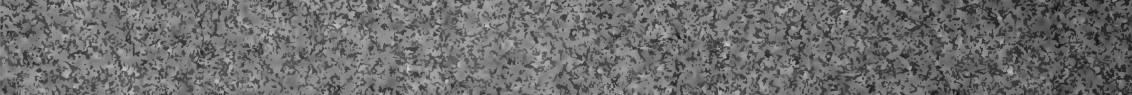

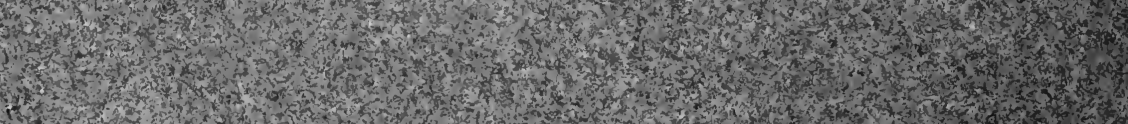

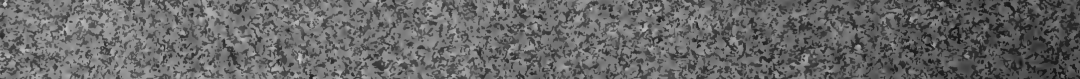

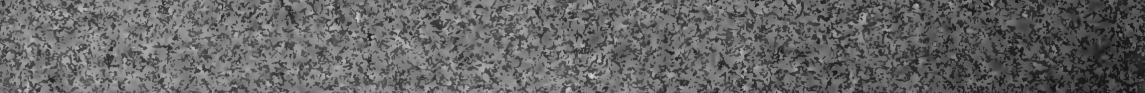
H.

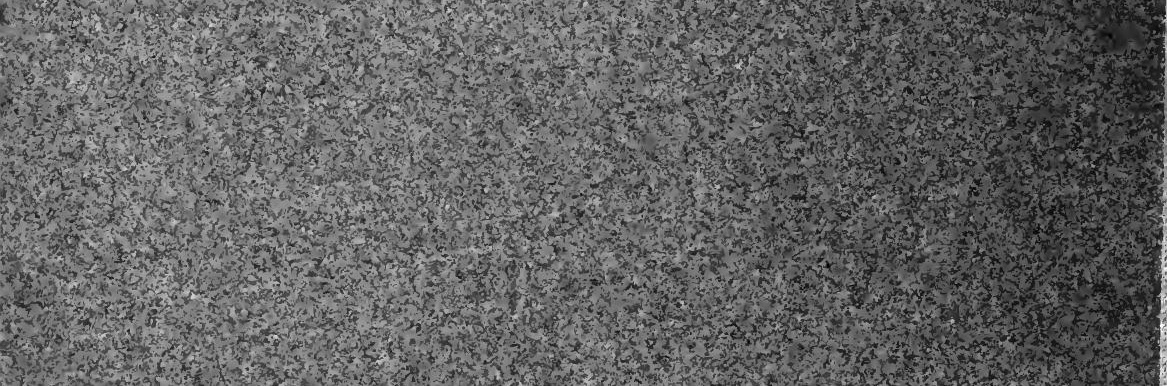

